Article

\title{
Performance of Laser-Based Electronic Devices for Structural Analysis of Amazonian Terra-Firme Forests
}

\author{
Iokanam Sales Pereira ${ }^{1}\left(\mathbb{D}\right.$, , Henrique E. Mendonça do Nascimento ${ }^{2}$, Matheus Boni Vicari ${ }^{3}{ }^{(D)}$, \\ Mathias Disney ${ }^{3,4}{ }^{\circledR}$, Evan H. DeLucia ${ }^{5}{ }^{\oplus}$, Tomas Domingues ${ }^{6}{ }^{\oplus}$, Bart Kruijt ${ }^{7}$, David Lapola ${ }^{8}$, \\ Patrick Meir ${ }^{9,10}$, Richard J. Norby ${ }^{11}$, Jean P.H.B. Ometto ${ }^{12} \oplus$, Carlos A. Quesada ${ }^{1}$, \\ Anja Rammig ${ }^{13}$ and Florian Hofhansl ${ }^{14, *(1)}$
}

1 Coordenação de Dinâmica Ambiental, Instituto Nacional de Pesquisas da Amazônia, Av. André Araújo 2936, Petrópolis, Manaus, AM 69067-375, Brazil; iokanam.eng@gmail.com (I.S.P.); quesada.beto@gmail.com (C.A.Q.)

2 Coordenação de Biodiversidade, Instituto Nacional de Pesquisas da Amazônia, Av. André Araújo 2936, Petrópolis, Manaus, AM 69067-375, Brazil; henrique@inpa.gov.br

3 Department of Geography, University College London, Gower Street, London WC1E 6BT, UK; ucfambo@ucl.ac.uk (M.B.V.); mathias.disney@ucl.ac.uk (M.D.)

4 NERC National Centre for Earth Observation, University of Leicester, University Road, Leicester LE1 7RH, UK

5 University of Illinois Urbana-Champaign, Department of Plant Biology, Institute For Sustainability, Energy, and Environment, Urbana, IL 61801, USA; delucia@life.illinois.edu

6 Faculdade de Filosofia, Ciências e Letras (FFCLRP-USP) Ribeirão Preto, Ribeirão Preto, SP 14040-900, Brazil; tdomingu@gmail.com

7 Department of Environmental Sciences, Wageningen University, 6700AA Wageningen, The Netherlands; bart.kruijt@wur.nl

8 Center for Meteorological and Climatic Research Applied to Agriculture, University of Campinas, Campinas, SP 13083-886, Brazil; dmlapola@unicamp.br

9 School of Geosciences, University of Edinburgh, Edinburgh EH9 3JN, UK; pwmeir@gmail.com

10 Research School of Biology, The Australian National University, Canberra, ACT 2601, Australia

11 Environmental Sciences Division and Climate Change Science Institute, Oak Ridge National Laboratory, Oak Ridge, TN 37831-6301, USA; norbyrj@ornl.gov

12 Center for Earth System Science, National Institute for Space Research, São José dos Campos, SP 12227-010, Brazil; jeanometto@gmail.com

13 School of Life Sciences Weihenstephan, Technical University of Munich, Hans-Carl-von-Carlowitz-Platz 2, 85356 Freising, Germany; anja.rammig@tum.de

14 International Institute for Applied Systems Analysis (IIASA); Schlossplatz 1, Laxenburg A-2361, Austria

* Correspondence: hofhansl@iiasa.ac.at; Tel.: +43-(0)-2236-807-544

Received: 30 December 2018; Accepted: 26 February 2019; Published: 2 March 2019

check for updates

\begin{abstract}
Tropical vegetation biomass represents a key component of the carbon stored in global forest ecosystems. Estimates of aboveground biomass commonly rely on measurements of tree size (diameter and height) and then indirectly relate, via allometric relationships and wood density, to biomass sampled from a relatively small number of harvested and weighed trees. Recently, however, novel in situ remote sensing techniques have been proposed, which may provide nondestructive alternative approaches to derive biomass estimates. Nonetheless, we still lack knowledge of the measurement uncertainties, as both the calibration and validation of estimates using different techniques and instruments requires consistent assessment of the underlying errors. To that end, we investigate different approaches estimating the tropical aboveground biomass in situ. We quantify the total and systematic errors among measurements obtained from terrestrial light detection and ranging (LiDAR), hypsometer-based trigonometry, and traditional forest inventory. We show that laser-based estimates of aboveground biomass are in good agreement $(<10 \%$ measurement uncertainty) with traditional measurements. However, relative uncertainties vary among the
\end{abstract}


allometric equations based on the vegetation parameters used for parameterization. We report the error metrics for measurements of tree diameter and tree height and discuss the consequences for estimated biomass. Despite methodological differences detected in this study, we conclude that laser-based electronic devices could complement conventional measurement techniques, thereby potentially improving estimates of tropical vegetation biomass.

Keywords: carbon storage; central-eastern Amazonia; forest structure; terra-firme forest; terrestrial laser scanning; light detection and ranging (LiDAR)

\section{Introduction}

Tropical vegetation holds the lion's share of the global terrestrial carbon (C) pool stored in aboveground plant biomass [1]. However, due to a lack of ground data available for tropical forests, our knowledge on how much biomass is stored in these ecosystems is still highly uncertain. Such uncertainties arise because in spite of ongoing initiatives, only a small proportion of this vast and spatially variable ecosystem has, so far, been surveyed by traditional forest inventories [2,3].

A general technique to measure aboveground biomass (AGB) in situ is to destructively sample and extract basic structural variables of the vegetation at the individual level and then to develop calibrated allometric (size-to-mass) relationships for upscaling to the plot-level based on biometric vegetation parameters $[4,5]$. The main horizontal structural vegetation parameters collected in forest inventories are the tree diameter at breast height (DBH), the stem basal area (BA), and number of individuals $(\mathrm{Ni})$; the main vertical variables are the total tree height $(\mathrm{Ht})$, the commercial height $(\mathrm{Hc})$, the leaf area index (LAI), and the canopy architecture [4-8]. Each of these estimated parameters is associated with measurement errors; therefore, it is important to identify the underlying sources and relative magnitudes of uncertainty as respective errors will add up in compound estimates of vegetation biomass [4]. Such errors are associated with uncertainties due to the deviation of tree trunks from a perfect circular shape (irregular trunks and/or buttresses) and to the rate of trunk circumference decline with height, branching patters, identification of highest point on a tree, as well as variability of wood density $(\rho)$ among species and within species from different areas [2-4]. For instance, it has been demonstrated that a 5\% error in tree diameter and a 10\% error in tree height and wood density can lead to a $21.6 \%$ uncertainty in estimates of aboveground biomass [9]. This highlights the importance of assessing the respective measurement errors and also indicates that cumulative errors could propagate to even larger uncertainties when incorporated into allometric equations for estimating aboveground biomass [5]. As a result, AGB estimates are dependent on the particular choice of allometric equations based on the set of variables used for parameterization [10] because these parameters vary in relation to the spatial heterogeneity of tropical landscapes and among surveyed tree communities [2-4].

Recently, novel technologies based on light detection and ranging (LiDAR) have proven successful for the calibration of allometric models and, thus, could represent a nondestructive alternative to traditional destructive sampling techniques [11]. LiDAR technology is able to determine the distance between the instrument and a specific object by measuring the timespan between the emission and return of a laser beam with millimetric precision [12] and, thus, is capable of creating three-dimensional images of a given object based on recording the returns of light pulses emitted from the device [12,13]. Depending on the scale of interest, three types of LiDAR are used for the analysis of vegetation structure in forest ecosystems, i.e., spaceborne, airborne, and terrestrial LiDAR. Spaceborne LiDAR is currently limited to 3 years of data and has a relatively large footprint of the order of tens of meters and, hence, does not provide wall-to-wall coverage. Airborne LiDAR provides higher spatial detail but covers relatively smaller spatial areas. Both have been successfully tested at the global [14,15], continental [16], and national levels [17] but are limited by cloud cover and penetration through the canopy. Terrestrial LiDAR is being used for a more detailed analysis of the complex vegetation 
structure sampled across smaller spatial areas $(<1$ ha) down to the level of single trees [18-20]. At the plot level, terrestrial laser scanning (TLS) allows the extraction of biometric variables, such as, leaf, branch, and trunk volume, as well as canopy architecture, with remarkable accuracy [12,21-23].

So far, studies evaluating the structural parameters using TLS have been conducted mostly in temperate forest ecosystems $[19,24-26]$, and this technique might be expected to be less successful in tropical forest ecosystems due to the high structural complexity of tropical vegetation [11,27-31]. One of the main limitations for laser-based technologies in forest environments is the occlusion of the laser beam by the vegetative material present in different layers of the forest stratum [32-35]. Moreover, the structural complexity of the environment was found to vary throughout the landscape in response to environmental gradients [30-33]. To cope with the resulting differences in complexity of structural parameters and to reduce the associated measurement errors between surveyed forest plots, the sampling protocols for each variable of interest have been established, focusing on standardization of methodologies among different forest sites and on a greater control of non-sample errors [36-41]. Accordingly, strategies for sampling campaigns conducted across tropical and temperate forest plots have been established that are capable of producing point clouds with a uniform point distribution and, thus, should allow for the intercomparison of metrics between instruments, plots, and over time [42]. Indeed, TLS has been reported to yield reliable estimates of structural vegetation parameters across different tropical ecosystems and biogeographic regions, such as Amazonian lowland rainforests [43,44], mangrove forests in southeastern Brazil [45], neotropical rainforests in Costa Rica [31], and palaeotropical forests in Malaysia [28,29]. These studies often reported a higher accuracy of remotely sensed estimates than those applying conventional methods investigating the vegetation structure based on traditional forest inventories [11,46,47]. However, to thoroughly assess the uncertainties of estimated vegetation biomass, it is necessary to compare the respective error metrics among different surveyed vegetation parameters and multiple methodologies applied under comparable in situ conditions and based on the same tree individuals.

To that end, we conducted an intensive measurement campaign in central-eastern Amazonian terra-firme forest (1) to compare the measurements of tree diameter and height obtained from traditional inventory techniques and laser-based electronic devices (i.e., terrestrial laser scanner, electronic caliper, and hypsometer); (2) to quantify the total error, the systematic error, and the random error for each of these techniques; and (3) to assess the overall uncertainty of the respective methods for estimating aboveground biomass in tropical forest ecosystems.

\section{Materials and Methods}

The study was conducted in the Cuieiras River Basin near the Experimental Station of Tropical Forestry (EEST) managed by the National Institute of Amazonian Research (INPA). The site represents one of the best-studied regions in the Central-Eastern Amazon and is located near "ZF-2" approx. $70 \mathrm{~km}$ north of Manaus, Brazil (2 $36^{\prime} 32.67 \mathrm{~S} ; 60^{\circ} 12^{\prime} 33.48 \mathrm{~W}$; Figure 1 and the following URL https:/ / www.inpa.gov.br/amazonface/arquivos/Amazon-FACE-Sciencie_Plan_ Implementation_Strategy.pdf). According to Köppen-Geiger, the climate of the region is classified as a rainy tropical climate, with average monthly temperatures varying from 24 to $27^{\circ} \mathrm{C}$ [48]. The mean annual precipitation is $2400 \mathrm{~mm}$ with a dry period between July, August, and September when monthly precipitation is less than $100 \mathrm{~mm}$ [48,49]. The soils are clayic Latosol with high clay content and low natural fertility [50]. The vegetation is characterized as a dense ombrophilous forest, and foregoing studies conducted in the same region reported that vegetation structure, i.e., stem density, canopy height, and aboveground biomass, is representative of the Amazonian terra-firme forest [51]. The vegetation exhibits a median canopy height of $30 \mathrm{~m}$, with emergent trees reaching $45 \mathrm{~m}$; the individual stems reach up to $120 \mathrm{~cm} \mathrm{DBH}$; and the basal area reaches between $28-30 \mathrm{~m}^{2} \mathrm{ha}^{-1}$ [52]. The average canopy cover was $87-89 \%$ (dry/wet season), leaf area index of $5.3-6.2 \mathrm{~m}^{2} / \mathrm{m}^{2}$ (dry/wet season) and plot mean tree density $(>10 \mathrm{~cm} \mathrm{DBH})$ was 708 individuals ha ${ }^{-1}$. The main families found were Lecythidaceae, Sapotaceae, Arecaceae, Euphorbiaceae, Burseraceae, and Chrysobalanaceae. The largest 
number of species was found in Chrysobalanaceae, Sapotaceae, and Lauraceae [53]. Tree individuals (inclusion limit DBH $\geq 10 \mathrm{~cm}$ ) located in a permanent monitoring transect are monitored since 1996 by the Forest Management Laboratory at the National Institute for Amazonian Research (LMF/INPA). In this study, we evaluate traditional and laser-based inventory techniques based on surveying tree stems $\left(\mathrm{n}=55 ; \mathrm{DBH} \geq 10 \mathrm{~cm}\right.$ ) located inside circular plots with $30 \mathrm{~m}$ in diameter $\left(706 \mathrm{~m}^{2}\right)$ within a permanent monitoring transect managed by the National Institute of Amazonian Research (Figure 1).

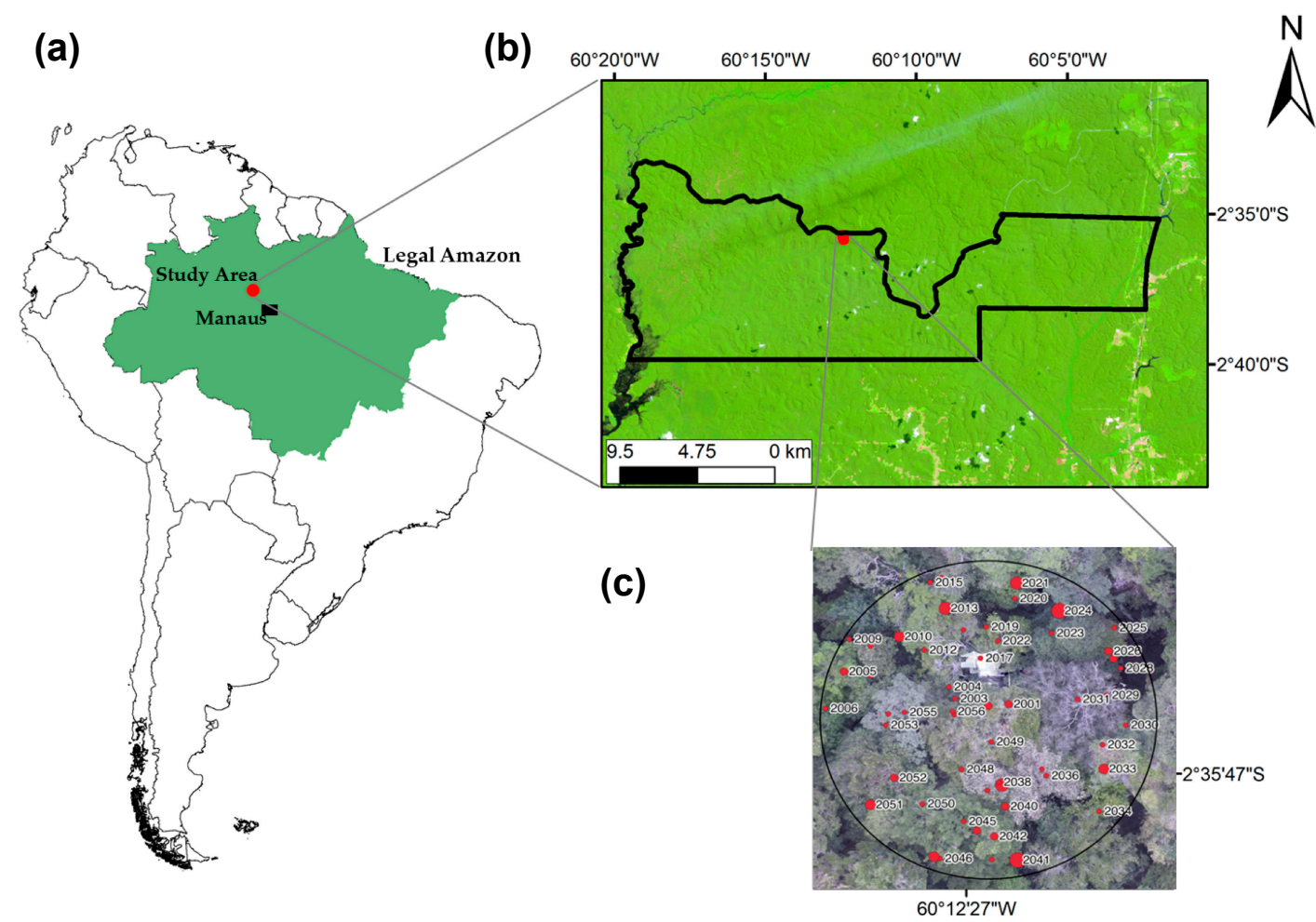

Figure 1. The locations of the monitoring plots in a central-eastern Amazonian terra-firme forest (situated in the study area ca. $70 \mathrm{~km}$ north of Manaus, Brazil): (a) The red points represent the geographic location of the survey plots situated in the Cuieiras Biological Reserve (delineated by the black border (b)), as well as the respective location and diameter size of individual trees analyzed in this study (identified by the respective point size and labeled by individual tree IDs (c)).

\subsection{Measurements Obtained with Traditional Forest Inventory Techniques}

For $\mathrm{DBH}$, the tree circumference was measured at $1.30 \mathrm{~m}$ above ground level using a $5 \mathrm{~m}$ diameter tape (Forestry Supplies, Mississippi, USA). In the case of imperfections or buttresses, the point of measurement (POM) was moved up until the form of the stem normalized following the RAINFOR protocol [38] and this observation was annotated in field worksheets. Additionally, the POM was marked with oil-based paint [36,38]. For Ht, the measurements were obtained with a tape measure of $50 \mathrm{~m}$ length (Irwin Tools, North Carolina, USA) at the highest possible point of the tree of interest that could be reached by a professional climber [54,55]. If the highest point was not reached by climbing, a measuring rod was used to reach the highest point of the crown.

In this study, the above-described traditional measurements (TM) of diameter and tree height were compared to estimates of $\mathrm{Ht}$ and $\mathrm{DBH}$ from multiple electronic devices, i.e., a laser rangefinder (TruPulse 360R, Laser Technology Inc., Colorado, USA; Figure 2a) coupled to an electronic caliper (BT MEM, Masser OY, Rovaniemi, Finland; Figure 2b) and connected to a portable computer (Getac T800, Hsinchu County, Taiwan; Figure 2c) integrated via the so-called Field-Map ${ }^{\circledR}$ software bundle (Institute of Forest Ecosystem Research Ltd., Prague, Czech Republic), as well as a terrestrial laser scanner (RIEGL VZ400, Riegl, Horn, Austria; Figure 2d). 


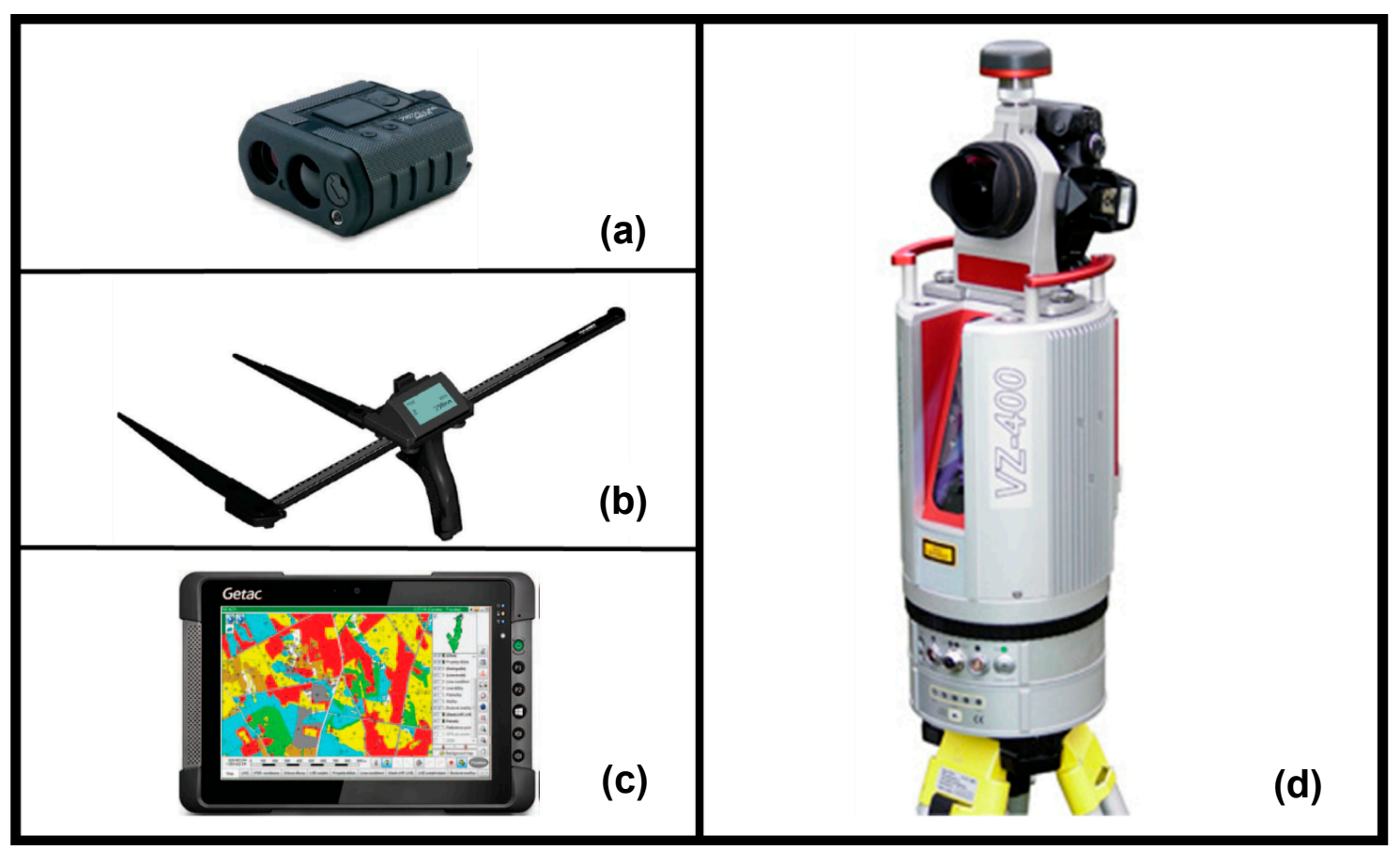

Figure 2. Electronic devices for the measurement of biometric variables: (a) Trupulse 360R, (b) BT MEM electronic caliper, (c) Getac T800 portable computer with Field-Map ${ }^{\circledR}$ software bundle, and (d) TLS RIEGL VZ400.

\subsection{Measurements Obtained with the Field-Map Bundle}

The field-map bundle is composed of three devices (Figure 2a-c). For the evaluation of DBH, two perpendicular $\left(90^{\circ}\right)$ measurements were taken from the trunk at the largest and smallest diameters using an electronic caliper (Figure 2b); at the same, POM as measured with the diameter tape. For the evaluation of $\mathrm{Ht}$, a laser rangefinder (LR, Figure 2a) was used to triangulate following the tangent method [56]. The electronic devices are wirelessly connected to a portable computer (Figure 2c) where data can be accessed directly in the field and extracted later via portable media (e.g., memory card or pen drive) or sent over wireless networks (Bluetooth). The Field-Map ${ }^{\circledR}$ software interface allows the user to note additional observations for each measurement, e.g., change in POM, presence of imperfections, and buttress of the trunk. The device also determines the positions of each tree individual $(x, y, z$ coordinate system) by conducting distance measurements between respective tree individuals and a reflecting target in the center of the plot (considered as the center of the $x, y$, and $z$ coordinates). This information is used by the Field-Map software to display the position of each tree on a two-dimensional map on the computer screen. Later on, this spatially explicit information was used to locate and co-register tree segments identified by the terrestrial laser scan.

\subsection{Measurements Obtained with Terrestrial Laser Scanning}

\section{Terrestrial Laser Scanning}

Three-dimensional scans were performed with the RIEGL VZ-400 laser scanner (Figure 2d). The device has a vertical angle range of $30-130^{\circ}$ and quickly acquires a large amount of data (300 kHz laser beam repetition rate) by recording multiple laser pulse returns (up to four returns per pulse emitted). The beam divergence of the laser is $0.35 \mathrm{mrad}$ operating in the near infrared range (wavelength $1550 \mathrm{~nm}$ ) and records targets within a range of $350 \mathrm{~m}$. The scan settings were standardized across multiple scan positions throughout the plot. Briefly, we used a systematic sampling scheme using a central scanning location and further scanning sites in each cardinal direction to cover the plot area by conducting eight to ten overlapping scans with a mean distance below $10 \mathrm{~m}$. Data were 
collected using the high-speed mode to obtain the maximum amount of laser return points per time, thus improving identification of the forest structure. Furthermore, additional scans were acquired at each scanning location with the instrument tilted $90^{\circ}$ from the vertical position to fully sample the canopy. The collection time per position was approximately $2 \mathrm{~min}$ for the vertical position and for the tilted $\left(90^{\circ}\right)$ positions. To register the respective scans into a single point cloud, reflective targets made from reflective tape glued onto plastic cylinders $5 \mathrm{~cm}$ in diameter and $10 \mathrm{~cm}$ in height [42] were distributed throughout the plot.

\section{Registration of the Point Cloud}

The scenes generated by each scan in the previous step were aligned in a common coordinate system forming a single point cloud for the entire plot (Figure 3). This process is defined as the point cloud registration $[42,57,58]$. The process was performed automatically using the RiSCAN PRO software [59]. The program usually identifies at least four reflective targets shared by each scanning location, which is considered the minimum number to perform a reasonable coarse registration between two consecutive scans [60]. However, the more reflective targets that can be detected during the scanning process, the better the automated registration procedure will perform (Figure 3).

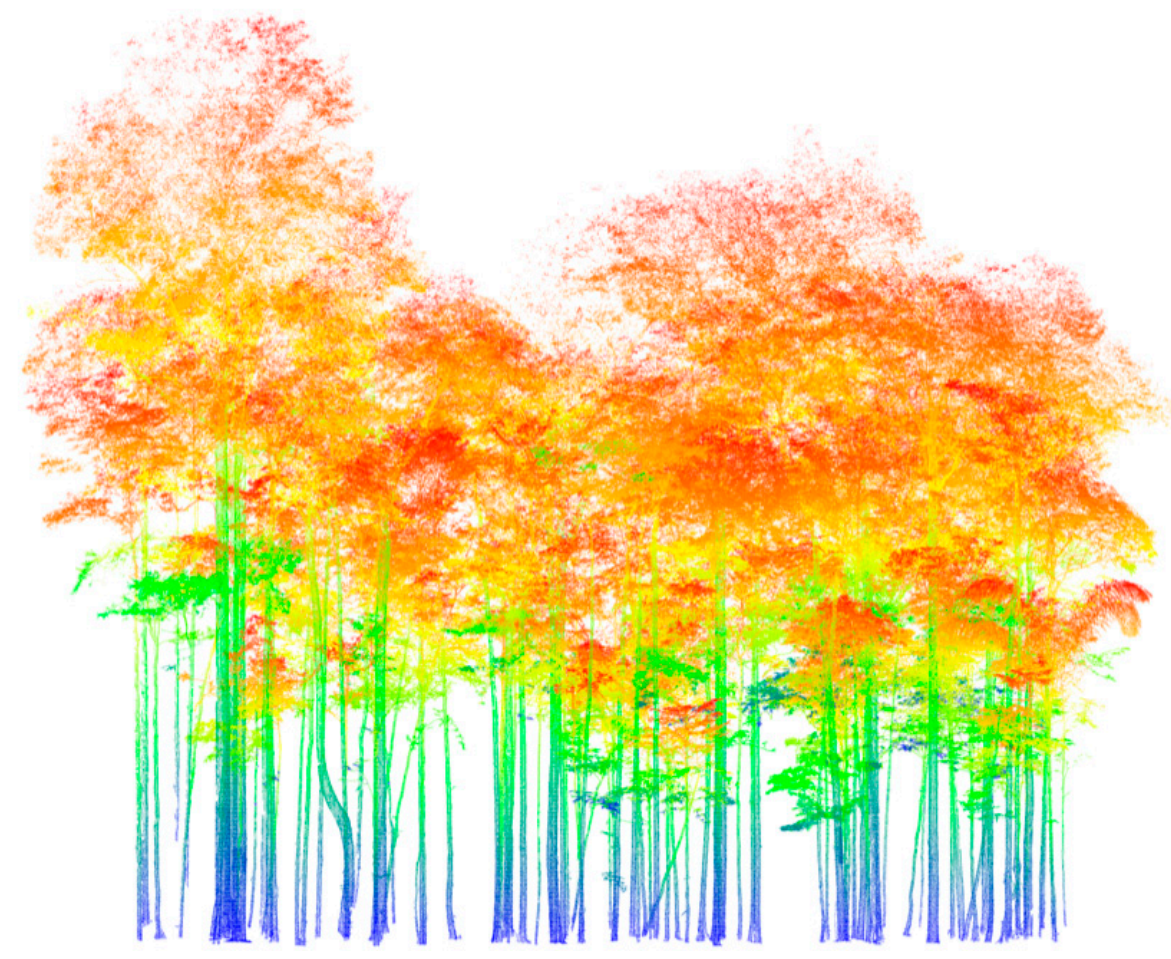

Figure 3. Example imagery of terrestrial laser scanning conducted in an eastern-central Amazonian terra-firme forest using a RIEGL VZ400. Differences in laser beam density are color-coded blue to red from high to low reflection density.

\section{Extracting Individual Trees}

The treeseg library (https:/ / github.com/apburt/treeseg) was used to extract a point cloud for each individual tree [43]. This library is based on custom algorithms that depend on other open-source libraries such as the Point Cloud Library (http:/ / pointclouds.org), which provides software processing the point cloud [61]. The semiautomatic extraction of each tree in the point cloud generated by multiple scanning was performed by the following steps: (i) tree identification by removing ground points, obtaining vertical slices of the cloud, and fitting cylinders to potential trunks; (ii) the segmentation of each stem up to the position of first branching using Euclidean clustering to remove any neighboring vegetation and assessing the goodness of cylinder fitting from the previous step; (iii) the extraction 
of the crown from each stem detected by generating a volume of canopy and using a region-based segmentation; and (iv) the visual inspection of the point cloud and, if necessary, manual removal of misidentified points due to neighboring vegetation [43,46,62].

\section{Acquisition of Biometric Variables from the Point Cloud}

Following the procedure above, point coordinates for each individual tree were generated using open-source software for point cloud analysis (3D Forest version 0.42 ; available from www.3dforest. eu; [63]). The software extracts horizontal and vertical structural variables such as DBH, Ht, position of the tree, and volume of sections of the trunk, as well as canopy-related variables such as base height, crown depth, crown area, and volume. For the DBH estimation, we applied two methods: (i) Randomized Hough transformation (TLS $\mathrm{RHT}_{\mathrm{T}}$ ) fitting a circle to the horizontal section of the trunk, with an adjusted number of iterations (standard setting $n=200$ ) [64], and (ii) least squares regression $\left(\right.$ TLS $\left._{\text {LSR }}\right)$ with an algebraic estimation of the diameter and reduction of the quadratic distance of the adjusted circle [65]. The two methods use only part of the point cloud, i.e., a $10 \mathrm{~cm}$ horizontal section of the trunk between 1.25 and $1.35 \mathrm{~m}$ above the lowest point determined by the digital terrain model [63] (Figure 4). For the extraction of diameters in a position different from the conventional POM $(1.30 \mathrm{~m})$, the stem curve command is able to determine the diameter in different positions of the trunk. The diameters in the stem curve command are located, relative to the base of the cloud, at $0.65 \mathrm{~m}, 1.3 \mathrm{~m}, 2 \mathrm{~m}$, and every $1 \mathrm{~m}$ until the first bifurcation of the trunk. The stem curve command terminates when the estimated diameter is twice as large as the two diameters above, which indicates the crown expansion in the point cloud [63].

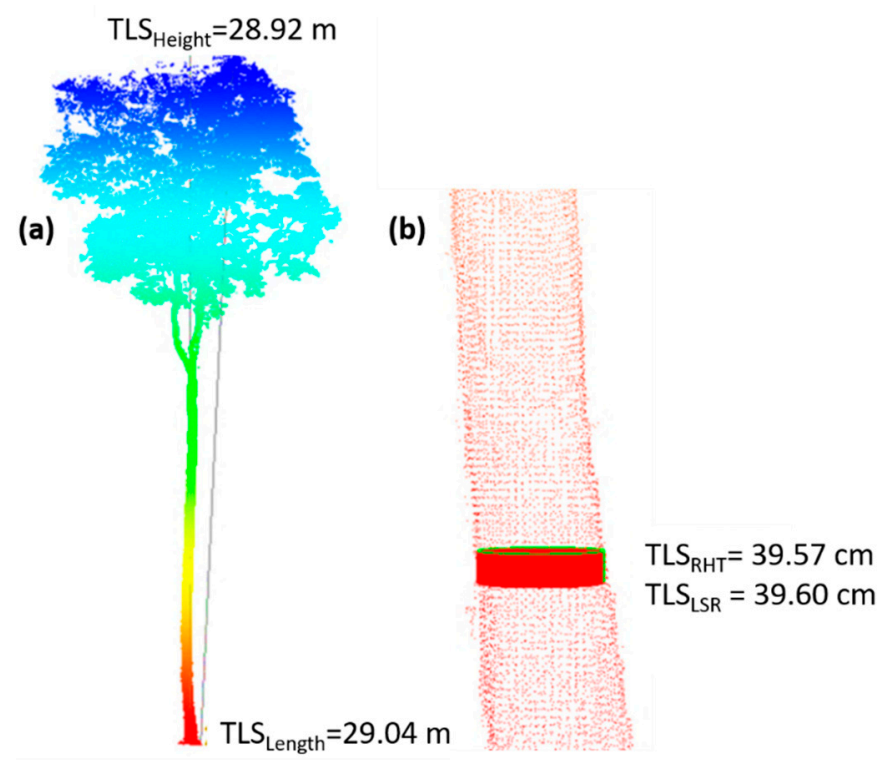

Figure 4. An example of a point cloud and biometric variables obtained with 3D Forest: (a) An example for estimating the total tree height $\left(\mathrm{TLS}_{\mathrm{Height}}=28.92 \mathrm{~m}\right)$ and the length of the point cloud $\left(\mathrm{TLS}_{\text {Length }}=29.04 \mathrm{~m}\right)$ and $(\mathbf{b})$ an example for estimating the diameter at breast height $(\mathrm{DBH})$ based on a randomized Hough transformation $\left(\mathrm{TLS}_{\mathrm{RHT}}=39.57 \mathrm{~cm}\right)$ and a least squares regression $\left(\mathrm{TLS}_{\mathrm{LSR}}=\right.$ $39.60 \mathrm{~cm}$ ). Note that the estimates of stem height and stem length differ due to an inclination of the tree stem, whereas the estimates of diameter vary due to the different mathematical formulations of the stem-fitting algorithm.

For estimates of total tree height $(\mathrm{Ht})$, the program offers two different approaches: (i) The "TLS Height" method defines the height by calculating the difference between the highest and the lowest points in the cloud along the z-axis (ii) the "TLS Length" method that computes the largest Euclidean distance between a point at the base of the cloud and the farthest point in any direction of the cloud, thus being the method of choice for analyzing inclined trees [63] (Figure 4). 


\subsection{Data Analysis}

The relationship between traditional inventory measurements (TM) and laser-based estimates of tropical vegetation structure (i.e., tree diameter and tree height) obtained either with the Fieldmap bundle (FM) or the terrestrial laser scanner (TLS) was assessed using reduced major axis regression (RMA) [66]. For each instrument, the total error, the systematic error (i.e., accuracy), and the random error (i.e., precision) were quantified [56]. The total error (Equation (1)) was evaluated based on root mean square error (RMSE):

$$
\text { Total Error }(E t)=\sqrt{\frac{1}{n} \Sigma\left(x_{\text {predicted }}-x_{\text {observed }}\right)^{2}}
$$

The systematic error (Equation (2)) or bias was calculated as the mean of the measurement error (Equation (2)) and represents "a mean of the differences between population measurements or test results and an accepted reference or true value" [67]. It was calculated as follows:

$$
\text { Systematic error }(E s)=\frac{1}{n} \Sigma\left(x_{\text {predicted }}-x_{\text {observed }}\right)
$$

The random error (Equation (3)) considers the variation of the measurement errors and represents the "statistical variance of an estimation methodology" [68], calculated as follows:

$$
\text { Random error }(E r)=\sqrt{\frac{1}{n} \Sigma\left(x_{\text {predicted }}-x_{\text {observed }}-E s\right)^{2}}
$$

Due to errors increasing in absolute terms with the DBH and $\mathrm{Ht}$, all the abovementioned errors were calculated in a proportional way. The proportional total error, proportional systematic error, and proportional random error were calculated according to the following equations (Equations (4)-(6)):

$$
\begin{gathered}
\text { Total Error prop }\left(E t_{\text {prop }}\right)=\sqrt{\frac{1}{n} \Sigma\left(\frac{x_{\text {predicted }}-x_{\text {observed }}}{x_{\text {observed }}}\right)^{2}} \\
\text { Systematic error prop }=\Sigma\left(\frac{x_{\text {predicted }}-x_{\text {observed }}}{x_{\text {observed }}}\right) \\
\text { Random error prop }=\sqrt{\frac{1}{n-1} \Sigma\left(\frac{x_{\text {predicted }}-x_{\text {observed }}}{x_{\text {observed }}}-E_{\text {prop }}\right)^{2}}
\end{gathered}
$$

where $X_{\text {observed }}$ is the actual measurement for the desired variable, e.g., for DBH, the data obtained from the diameter tape (i.e., by calculating DBH from the circumference measurements) or for $\mathrm{Ht}$ obtained with a vertical tape measurement; $X_{\text {predicted }}$ refers to the biometric data obtained with the electronic devices, i.e., FM and TLS; and $n$ the number of trees. Briefly, the systematic error indicates the tendency of an instrument to record results systematically above or below the actual value (i.e., precision), whereas the random error is the product of the variations in measurements that do not follow a fixed trend and the total error is the product of the estimate (systematic and random error) in relation to the observed in situ measurement (i.e., accuracy).

The DBH and Ht obtained through the conventional measurements and the instruments assessed in this study were used as input variables for allometric equations estimating tropical aboveground biomass (AGB). We selected two local equations, derived from central Amazonian inventory plots, and two pantropical equations extracted from the published literature $[5,10,69]$ (see references in Appendix A Table A1). The local equation proposed by Higuchi et al. [69] was used as a reference for calculating the error metrics among AGB estimates resulting from different allometric relationships evaluated in this study. The equation is based on fresh weight from destructively sampled trees and applies a correction factor of 0.6028 ( 1 - mean moisture content) [70]. 


\section{Results}

\subsection{Analysis of Horizontal Vegetation Structure (Tree Diameter)}

Regardless of the instrument used, the estimated DBHs were in good agreement with the measurements obtained with a diameter tape and centered around the 1:1 line for class $\mathrm{DBH}_{10-30}$ $\mathrm{cm}$ and $\mathrm{DBH}_{\mathrm{All}}$ (Figure 5). However, for both size classes, the coefficient of determination $\left(\mathrm{R}^{2}\right)$ for measurements conducted with the electronic caliper (each $\mathrm{R}^{2}=0.99$ ) was slightly higher than the estimates derived from TLS using both methods $\mathrm{TLS}_{\mathrm{RHT}}\left(\mathrm{R}^{2}=0.93\right.$ and 0.96 for class $\mathrm{DBH}_{10-30}$ and all trees, respectively) and TLS $L S R\left(R^{2}=0.94\right.$ and 0.96 , respectively). Such differences in $R^{2}$ among the different methods were related to respective random errors. Estimates from the electronic caliper exhibited a relatively low random error $\left(\operatorname{Er}_{\text {prop }}=2.2 \%\right.$ and $\left.2.3 \%\right)$ compared to estimates from TLS $S_{\text {RHT }}$ $(11.6 \%$ and $11.0 \%)$ and TLS $_{\text {LSR }}(10.4 \%$ and $10.1 \%)$. Systematic errors (i.e., errors within methods) were smaller in magnitude when compared to random errors for all three methods and both size classes. TLS $_{\mathrm{RHT}}$ exhibited a low systematic error for class $\mathrm{DBH}_{10-30}$. However, this might be a mathematical artifact because negative deviations cancel out positive deviations and vice versa, and therefore, systematic errors can be close to zero (Table 1).
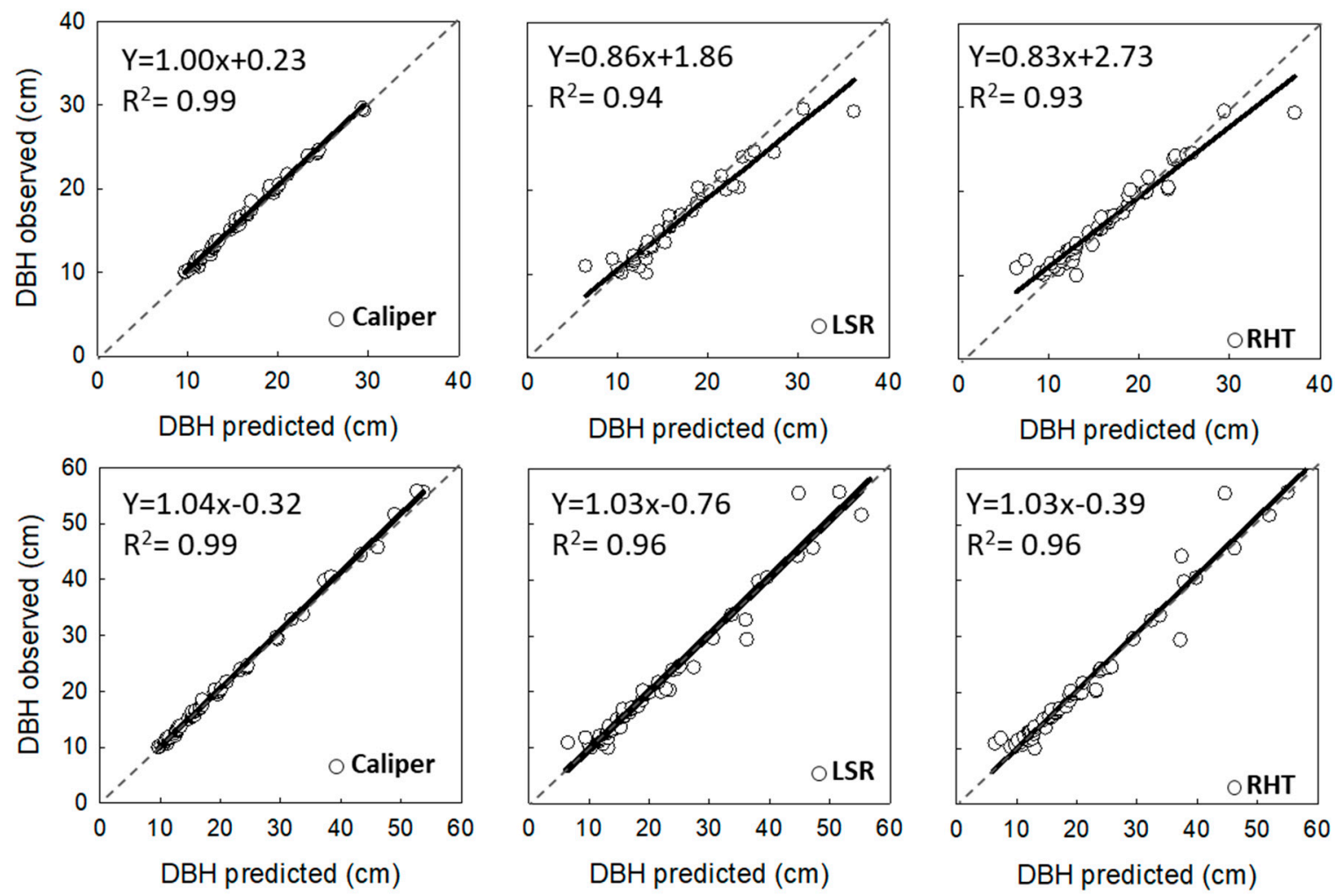

Figure 5. The observed (tape measured) DBHs versus the DBH measured with the caliper from the field map bundle and extracted from the terrestrial laser scanning (TLS) point cloud using two different

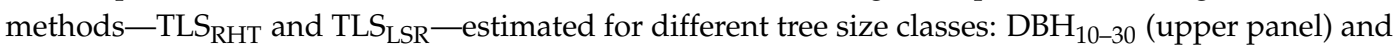
$\mathrm{DBH}_{\mathrm{All}}$ (lower panel): The solid lines represent the adjusted linear models, and the dashed lines represents the $1: 1$ lines $(Y=X)$. 
Table 1. A summary of the errors in estimated DBHs for different measurement methods relative to the observed (tape measure) DBHs for different size-classes of tropical trees: The errors are shown in absolute and proportional terms, respectively.

\begin{tabular}{|c|c|c|c|c|c|c|}
\hline \multirow{2}{*}{ Method } & \multicolumn{2}{|c|}{ Total Error } & \multicolumn{2}{|c|}{ Systematic Error } & \multicolumn{2}{|c|}{ Random Error } \\
\hline & Et $(\mathrm{cm})$ & $E t_{\text {prop }}(\%)$ & Es $(\mathrm{cm})$ & Es $_{\text {prop }}(\%)$ & $\operatorname{Er}(\mathrm{cm})$ & $\mathrm{Er}_{\text {prop }}(\%)$ \\
\hline \multicolumn{7}{|c|}{$10 \leq \mathrm{DBH}<30 \mathrm{~cm}(\mathrm{n}=46)$} \\
\hline Caliper & 0.5 & 3.0 & -0.3 & -2.1 & 0.4 & 2.2 \\
\hline $\mathrm{TLS}_{\mathrm{RHT}}$ & 1.8 & 11.5 & $<0.1$ & -1.2 & 1.8 & 11.6 \\
\hline $\mathrm{TLS}_{\mathrm{LSR}}$ & 1.6 & 10.5 & 0.5 & 2.2 & 1.2 & 10.4 \\
\hline \multicolumn{7}{|c|}{ All trees $(n=55)$} \\
\hline Caliper & 0.9 & 3.2 & -0.5 & -2.3 & 0.7 & 2.3 \\
\hline $\mathrm{TLS}_{\mathrm{RHT}}$ & 2.4 & 11.1 & -0.4 & -1.8 & 2.4 & 11.0 \\
\hline $\mathrm{TLS}_{\mathrm{LSR}}$ & 2.3 & 10.2 & 0.2 & 1.6 & 2.0 & 10.1 \\
\hline
\end{tabular}

For the electronic caliper, the regression coefficients were close to 1 and the intercept close to 0 (Figure 5), whereas for TLS $\mathrm{RHT}_{\mathrm{RT}}$ and $\mathrm{TLS}_{\mathrm{LSR}}$, the regression coefficients were 0.86 and 0.83 and intercepts were 1.86 and 2.73, respectively, for class $\mathrm{DBH}_{10-30}$. In the class $\mathrm{DBH}_{\mathrm{All}}$, the coefficient keeps close to 1 and the intercept close to 0 for the caliper; for $T_{L S} S_{R H T}$ and $T_{L S} S_{L R}$, the regression coefficients the of the regression had a slight improvement when compared to coefficients in class $\mathrm{DBH}_{10-30}$.

In addition, the standard deviation of differences between the diameter tape measurements and the estimates obtained with the caliper was 3-5 times lower than for the estimates from TLS methods for both size classes (Figure 6a). In terms of accuracy (i.e., total errors of respective methods), the electronic caliper presented lower error values for both classes, $\mathrm{DBH}_{10-30}$ and $\mathrm{DBH}_{\mathrm{All}}$ (Table 1).
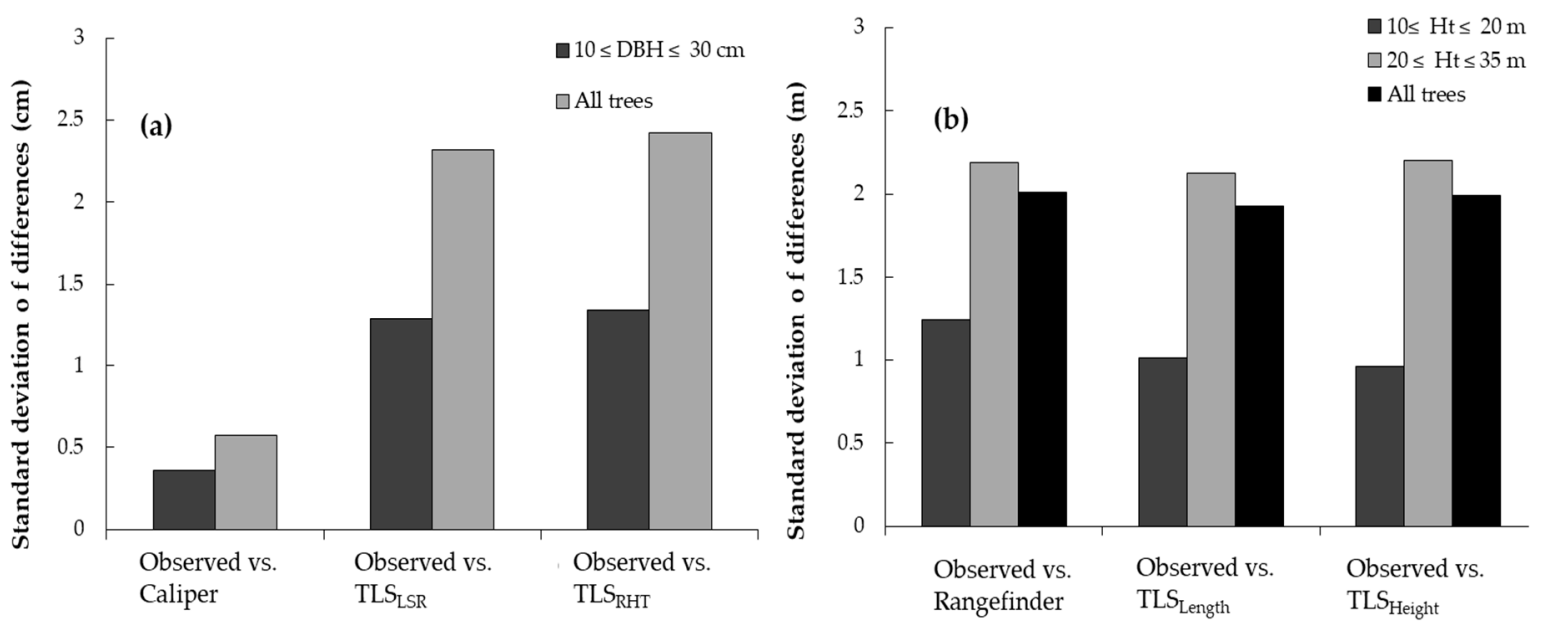

Figure 6. (a) The standard deviation of differences between the estimated versus observed diameter and for three different methods, i.e., traditional measurement (TM observed) vs. fieldmap (FM caliper) and terrestrial laser scanning $\left(\mathrm{TLS}_{\mathrm{RHT}}\right.$ and $\mathrm{TLS}_{\mathrm{LSR}}$ ), and (b) the standard deviation of differences between estimated versus observed tree height, i.e., measured manually (TM observed) versus fieldmap (FM rangefinder), as well as $\mathrm{TLS}_{\text {Length }}$ (tree length) and $\mathrm{TLS}_{\text {Height }}$ (tree height).

\subsection{Analysis of Vertical Vegetation Structure (Tree Height)}

Height estimates $(\mathrm{Ht})$ obtained from different instruments presented a relatively lower correspondence to direct observations of tree height obtained from vertical tape measurements (Table 2). 
Table 2. Metrics of error among the methodologies for predict the total height $(\mathrm{Ht})$ for trees with $\mathrm{Ht}$ between 10 and $20 \mathrm{~m}(\mathrm{n}=26)$, Ht between 20 and $35 \mathrm{~m}(\mathrm{n}=29)$, and for all trees $(n=55)$ : The errors are presented in absolute and proportional terms for respective measurements obtained from hypsometry using the laser rangefinder (Rangefinder), as well as the extraction of height $\left(\mathrm{TLS}_{\mathrm{Height}}\right)$ and length

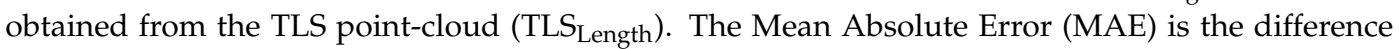
between the estimate and reference measurements.

\begin{tabular}{|c|c|c|c|c|c|c|c|}
\hline \multirow{2}{*}{ Methodology } & \multicolumn{2}{|c|}{ Total Error } & \multicolumn{2}{|c|}{ Systematic Error } & \multicolumn{2}{|c|}{ Random Error } & \multirow{2}{*}{$\begin{array}{c}\text { MAE } \\
\text { (m) }\end{array}$} \\
\hline & Et (m) & $\mathrm{Et}_{\text {prop }}(\%)$ & Es (m) & Es prop $(\%)$ & $\operatorname{Er}(\mathrm{m})$ & $\mathrm{Er}_{\text {prop }}(\%)$ & \\
\hline \multicolumn{8}{|c|}{ Height 10-20 m (n = 26) } \\
\hline Rangefinder & 1.9 & 11.9 & -0.3 & -2.0 & 1.9 & 12.0 & 1.5 \\
\hline TLS ${ }_{\text {Height }}$ & 1.8 & 10.2 & 0.9 & 4.9 & 1.2 & 9.1 & 1.2 \\
\hline TLS $_{\text {Length }}$ & 1.9 & 10.5 & 1.0 & 5.8 & 1.6 & 8.9 & 1.2 \\
\hline \multicolumn{8}{|c|}{ Height $20-35$ m $(n=29)$} \\
\hline Rangefinder & 3.1 & 11.5 & 1.00 & 3.9 & 2.9 & 11.0 & 2.1 \\
\hline TLS $S_{\text {Height }}$ & 2.4 & 9.8 & 0.5 & 2.5 & 2.2 & 9.6 & 1.7 \\
\hline $\mathrm{TLS}_{\text {Length }}$ & 2.4 & 9.7 & 0.7 & 3.2 & 2.3 & 9.3 & 1.7 \\
\hline \multicolumn{8}{|c|}{ Height all trees $(n=55)$} \\
\hline Rangefinder & 2.6 & 11.7 & 0.4 & 1.1 & 2.6 & 11.8 & 2.0 \\
\hline TLS ${ }_{\text {Height }}$ & 2.2 & 10.0 & 0.7 & 3.6 & 1.8 & 9.3 & 1.6 \\
\hline TLS $_{\text {Length }}$ & 2.2 & 10.1 & 0.9 & 4.5 & 2.0 & 9.1 & 1.6 \\
\hline
\end{tabular}

For trees with $\mathrm{Ht}_{10-20}$, the heights obtained from the laser rangefinder presented less accuracy $\left(R^{2}=0.62\right.$ and $\left.\operatorname{Er}_{\text {prop }}=12.0 \%\right)$ when compared with $\operatorname{TLS}_{\text {Height }}\left(R^{2}=0.77\right.$ and $\left.\operatorname{Er}_{\text {prop }}=9.1 \%\right)$ and $\mathrm{TLS}_{\text {Length }}\left(\mathrm{R}^{2}=0.75\right.$ and $\left.\mathrm{Er}_{\text {prop }}=8.9 \%\right)$. On the other hand, the three methods had similar precisions for height classes of $\mathrm{Ht}_{20-35}$ and $\mathrm{Ht}_{\text {all }}$, with a decrease in accuracy for the $\mathrm{TLS}_{\text {Height }}$ and $\mathrm{TLS}_{\text {Length }}$ for the $\mathrm{Ht}_{20-35}$ class, but accuracy improved when all tree individuals were considered (Figure 7). This gain in accuracy comes from the expected positive relationship between the number and accuracy of estimates (due to an increase in sample size; Figure A2). Conversely, the standard deviation of the differences was larger for height classes of $\mathrm{Ht}_{20-35}$ and $\mathrm{Ht}_{\text {all }}$ compared to $\mathrm{Ht}_{10-20}$ for the three methods (Figure 6b). In terms of accuracy, there is a clear tendency to overestimate tree heights derived from both TLS methods for the class of $\mathrm{Ht}_{10-20}$. The laser rangefinder, in turn, tends to underestimate smaller trees and overestimate larger trees, respectively (Figure 7).

In general, methodological differences in systematic and total errors were comparable among the three methods (Table 2). However, for all of the three methods, there was a tendency to overestimate large trees $\left(\mathrm{Ht}_{20-35}\right)$; the rangefinder tended to overestimate large trees (at the upper end of the range; cf. slope coefficient $>1$ ), and both TLS methods overestimated tree height of small trees (at the lower end of the range, cf. slope coefficient $<1$ ). Hence, using the hypsometer to estimate tree height tended to overestimate the largest trees with greater total heights, whereas there was a better correspondence between the estimated and observed heights using the TLS method, which indicates that the latter method was not prone to increasing errors with increasing tree size (as highlighted by regression coefficients close to 1 and intercepts closer to 0; Figure 7). 

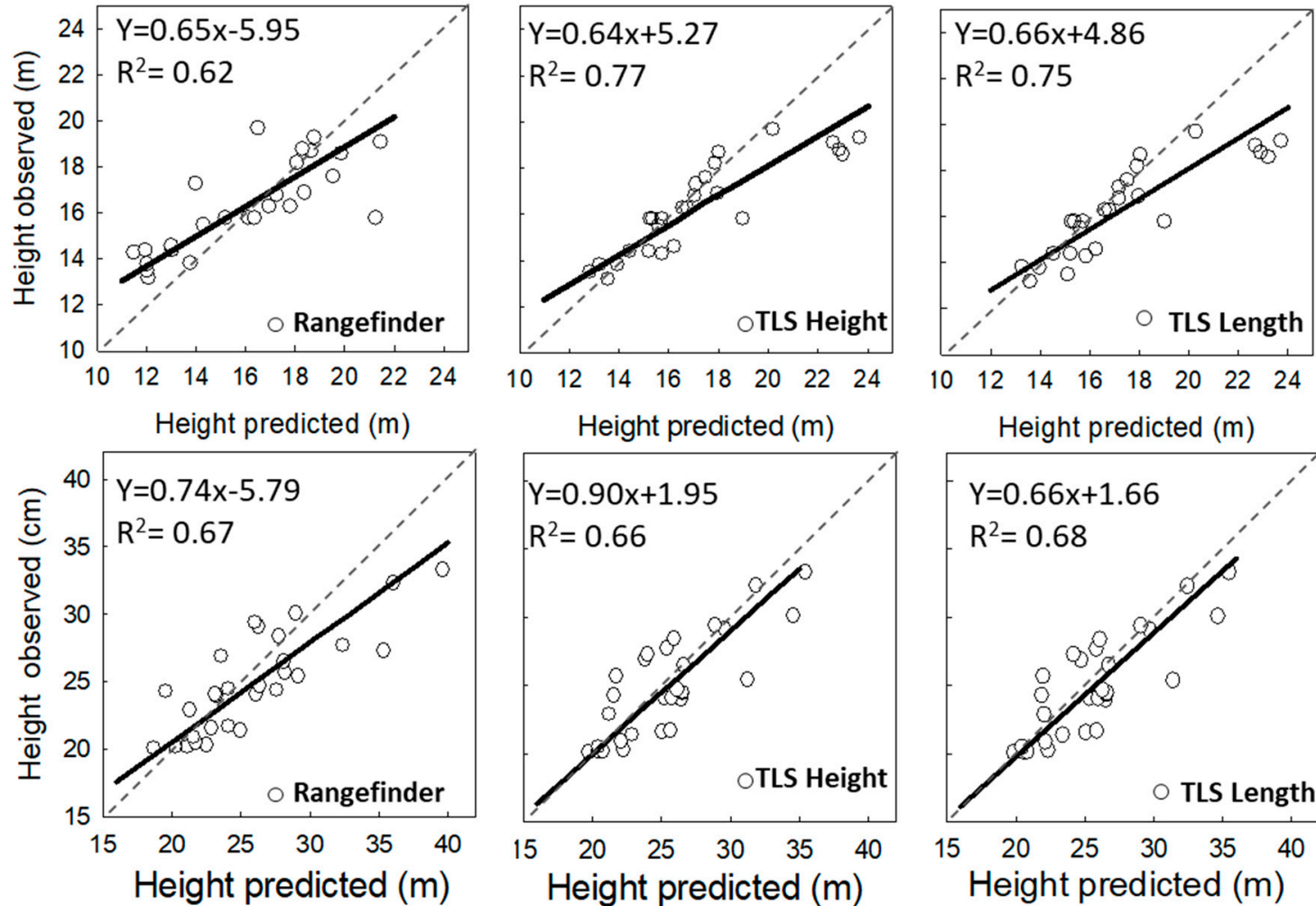

Height predicted $(\mathrm{m})$
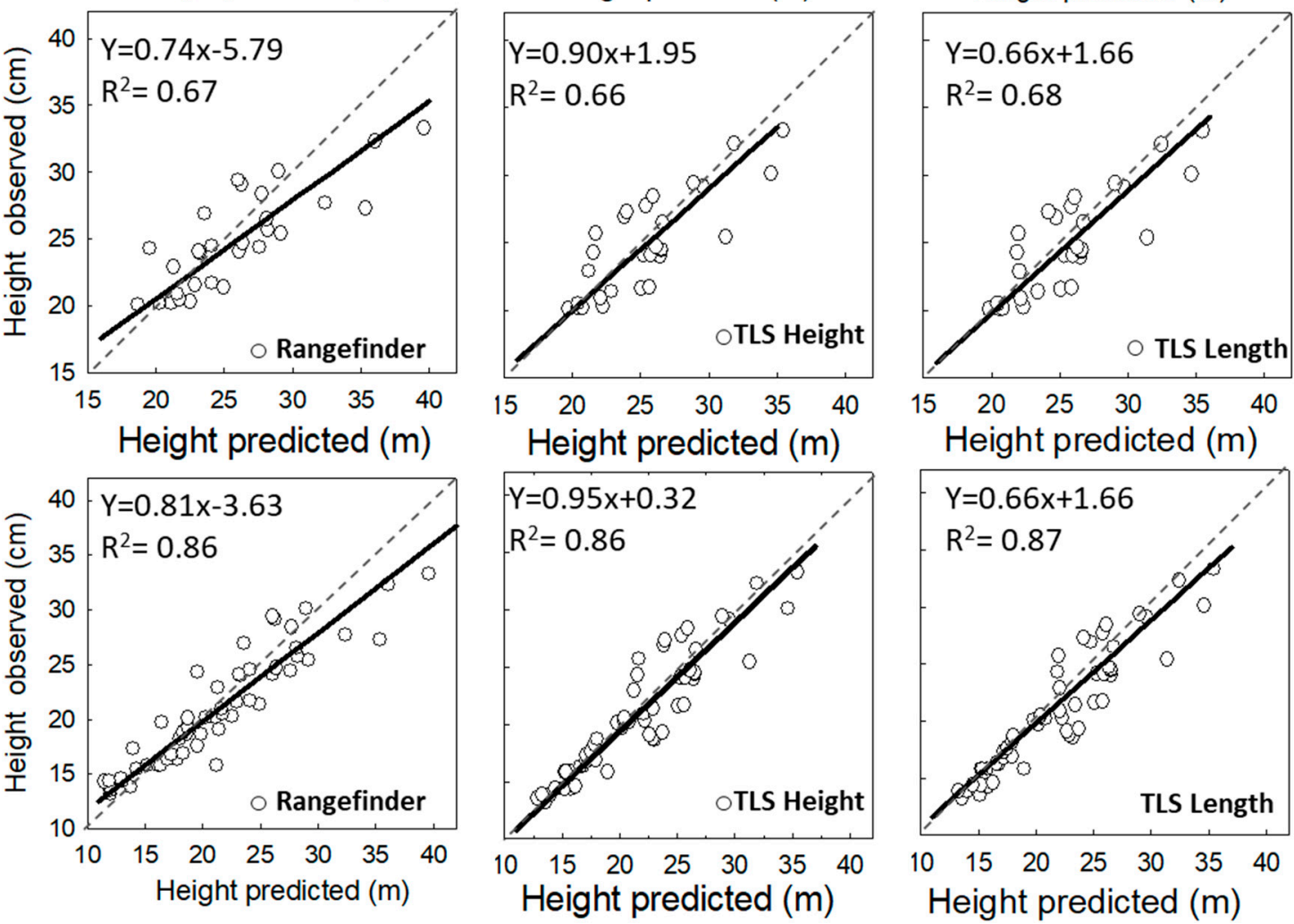

Figure 7. The observed (tape measured) tree height versus laser rangefinder, $\mathrm{TLS}_{\text {Height }}$, and $\mathrm{TLS}_{\text {Length }}$ estimates for different tree size classes: $10 \leq$ height $<20 \mathrm{~m}$ (upper panel), $20 \leq$ height $\leq 35 \mathrm{~m}$ (middle panel), and all trees (lower panel): The solid curves represent the adjusted linear models, and the dashed lines represents the $1: 1$ lines $(Y=X)$.

\subsection{Analysis of Compound Structural Parameters (Tree Biomass)}

Stem volume $\left(\mathrm{V}_{\text {stem }}\right)$ and basal area $(\mathrm{BA})$, exhibited values that were close to conventional measurements obtained with the diameter tape (Figure A1). However, estimates obtained with the $\mathrm{TLS}_{\mathrm{RHT}}$ method and the electronic caliper underestimated the reference measurement conducted with the diameter tape by $4.9 \%$ and $6.3 \%$ and with an RMSE of 0.20 and $0.09 \mathrm{~m}^{3}$, respectively, while the rangefinder method overestimated by only $0.1 \%$, however, with a high RMSE of $0.2 \mathrm{~m}^{3}$ (Figure A1). For all trees, $\mathrm{TLS}_{\mathrm{RHT}}$ and caliper measurements underestimated BA calculated from the tape measurement in 4.4 and $5.9 \%$ and with an RMSE of 146.7 and $61.4 \mathrm{~cm}^{2}$, respectively; BA calculated from the electronic caliper overestimated by $0.3 \%$ and with an RMSE of $145.9 \mathrm{~cm}^{2}$ (Figure A1). Structural parameters that are directly related to the number of individuals (e.g., basal volume and area) within an inclusion limit (usually $\mathrm{DBH} \geq 10 \mathrm{~cm}$ ) can be biased if a different number of tree stems 
are identified by respective methods (Figure A2). This difference is usually minimal on a plot scale (Figure A1) but can introduce large uncertainties when extrapolated to larger spatial scales.

The aboveground biomass estimates differed between allometric equations tested as well as within the same equations depending on the instrument used to collect the input variables to derive the allometric relationships among vegetation parameters and vegetation biomass (Figure 8).

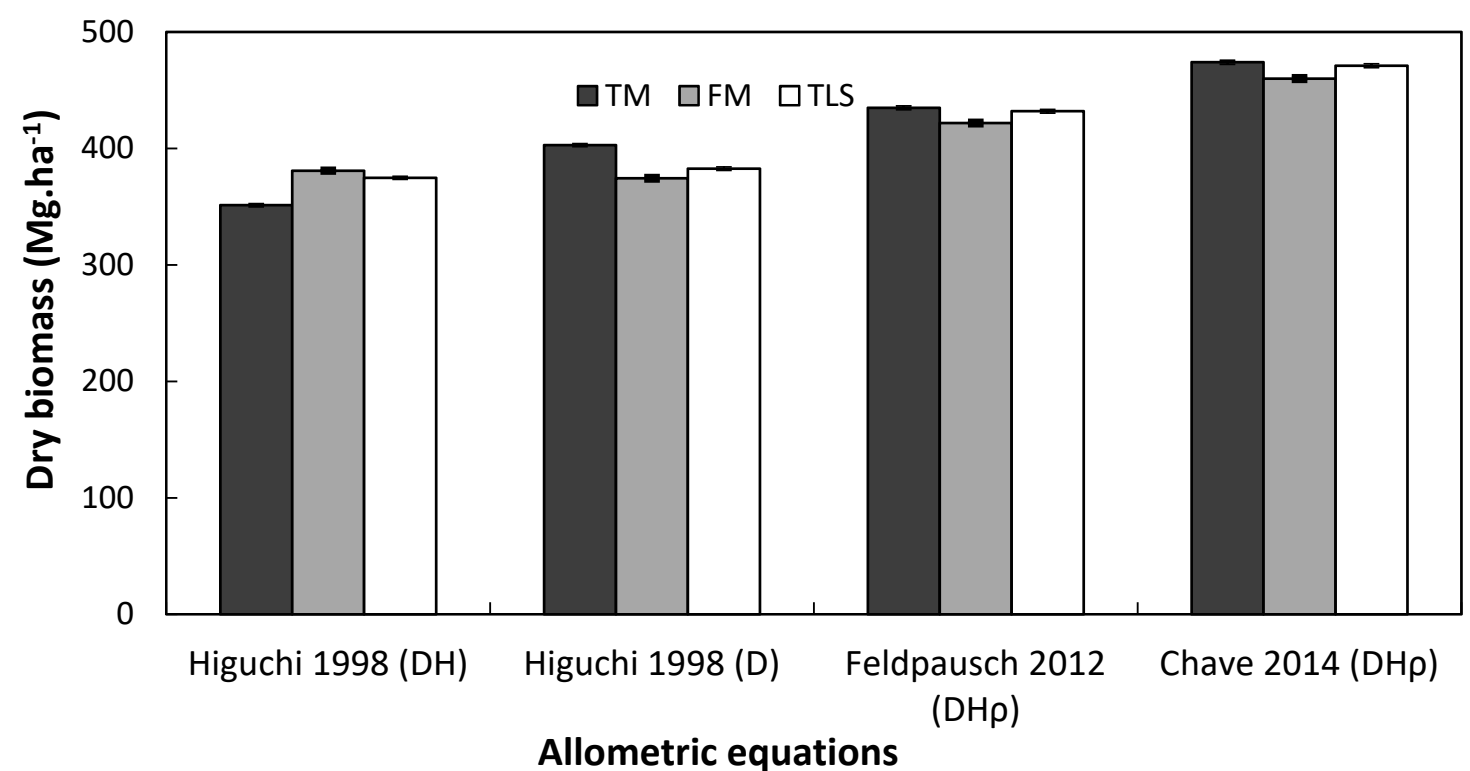

Figure 8. A bar chart showing the estimates of aboveground biomass based on different methods-tape measurement (TM), Field-Map bundle (FM), Terrestrial LiDAR (TLS)—-to calculate the estimates of aboveground biomass (using $\mathrm{DBH}_{\mathrm{RHT}}$ and $\mathrm{TLS}_{\mathrm{Height}}$ ) and based on different allometric equations (listed in Table A1) and assessing the vegetation parameters such as diameter ( $\mathrm{D}$ in $\mathrm{cm})$, height ( $\mathrm{H}$ in $\mathrm{m})$ and wood density ( $\rho$ in $\mathrm{g} \mathrm{cm}^{-3}$ ).

Here, we considered the allometric equation presented by Higuchi $1998(\mathrm{DH})$ as a reference estimate as it was based on measurements of tree diameter $(\mathrm{D})$ and tree height $(\mathrm{H})$ derived from a destructive harvest in a nearby forest area (cf. Table A1). Both estimates derived from electronic devices overestimated the manual reference estimate by $8.4 \%$ and $6.6 \%$, respectively (Table 3 ). The equation by Higuchi 1998 (D) considering only the diameter (D) as an input variable overestimated the aboveground biomass by $12.9 \%, 6.4 \%$, and $10.9 \%$ for diameter tape (TM), electronic caliper (FM), and TLS, respectively. The two pantropical equations using three parameters $(\mathrm{D}, \mathrm{H}$, and $\rho)$ overestimated aboveground biomass (Figure 8, Table 3): the equation by Feldpausch et al. 2012 overestimated the reference measurement by $14.8 \%, 10.7 \%$, and $17.5 \%$ for TM, FM, and TLS respectively; the equation by Chave et al. 2014 overestimated the reference measurement by $27.6 \%, 23.0 \%$, and $30.5 \%$ for TM, FM, and TLS respectively. As a result, the pantropical equations presented relatively large error metrics, such that applying the equations by Feldpausch and Chave resulted in total errors of up to $42-66 \%$ (Table 3).

In contrast, estimates derived from electronic devices, i.e., FM and TLS, overestimated the reference measurement (Figure 8, Figure A3) by $8.4 \%$ and $6.6 \%$, respectively. However, when calculating AGB estimates derived from electronic devices versus traditional inventory techniques within each of the allometric equations, the electronic devices underestimated the AGB estimates (Figure 8, Figure A3) due to a systematic error of $-2.4 \%$ and $-2.6 \%$ (Table 3). For all of the allometric equations considered in this study (Table A1), FM underestimated AGB by $7.0 \%, 3.0 \%$, and $2.9 \%$ for Higuchi et al. 1998 (D), Feldpausch et al. 2012, and Chave et al. 2014 respectively, whereas TLS underestimated AGB by $5.0 \%, 0.7 \%$, and $0.6 \%$ for Higuchi (D), Feldpausch, and Chave, respectively (Figure A3). 
Table 3. The metrics of error among the local and pantropical equations estimating tropical aboveground biomass: For each allometric equation, we used input data from respective instruments evaluated in this study, i.e., diametric/metric tape (TM), Field-Map bundle (FM), and terrestrial laser scanner (TLS). The Mean Absolute Error (MAE) is the difference between the respective estimate and the reference estimate based on the destructive sampling of local tree individuals. D, input is only diameter; $\mathrm{DH}$, input is diameter and height; $\mathrm{DH} \rho$, input is diameter, height, and wood density.

\begin{tabular}{|c|c|c|c|c|c|c|c|c|}
\hline \multirow{2}{*}{ Allometric Equation } & \multirow[b]{2}{*}{ Technology } & \multicolumn{2}{|c|}{ Total Error } & \multicolumn{2}{|c|}{ Systematic Error } & \multicolumn{2}{|c|}{ Random Error } & \multirow{2}{*}{$\begin{array}{c}\text { MAE } \\
\text { (kg) }\end{array}$} \\
\hline & & Et (kg) & $\mathrm{Et}_{\text {prop }}(\%)$ & Es (kg) & $E_{\text {prop }}(\%)$ & Er (kg) & $\operatorname{Er}_{\text {prop }}(\%)$ & \\
\hline iguchi $1998^{\mathrm{DH}}$ & FM & 403.1 & 31.0 & -28.1 & -2.4 & 405.9 & 31.2 & 179.2 \\
\hline Higuchi $1998^{\mathrm{DH}}$ & TLS & 277.3 & 26.6 & -36.1 & -2.6 & 274.9 & 26.8 & 125.4 \\
\hline Higuchi $1998^{D}$ & $\mathrm{TM}$ & 209.75 & 41.42 & 66.25 & 12.86 & 77.5 & 6.1 & 38.4 \\
\hline Higuchi $1998^{D}$ & FM & 191.9 & 39.7 & 29.9 & 6.4 & 200.6 & 26.3 & 70.9 \\
\hline Higuchi $1998^{\text {D }}$ & TLS & 182.3 & 52.1 & 40.4 & 10.9 & 200.8 & 24.3 & 104.5 \\
\hline Feldpausch 2012 DH $\rho$ & $\mathrm{TM}$ & 286.3 & 42.8 & 107.5 & 14.8 & 143.4 & 24.6 & 72.4 \\
\hline Feldpausch $2012 \mathrm{DH} \rho$ & FM & 268.3 & 41.7 & 90.7 & 10.7 & 190.3 & 26.9 & 82.4 \\
\hline Feldpausch $2012 \mathrm{DH} \rho$ & TLS & 288.7 & 56.8 & 103.8 & 17.5 & 233.7 & 33.6 & 102.3 \\
\hline Chave 2014 DH $\rho$ & $\mathrm{TM}$ & 351.4 & 51.4 & 157.8 & 27.6 & 192.3 & 27.2 & 106.7 \\
\hline Chave 2014 DH $\rho$ & FM & 328.5 & 49.2 & 139.8 & 23.0 & 224.1 & 29.6 & 105.0 \\
\hline Chave 2014 DH $\rho$ & TLS & 347.8 & 66.4 & 154.0 & 30.5 & 263.6 & 37.0 & 132.6 \\
\hline
\end{tabular}

\section{Discussion}

LiDAR-based remote sensing techniques provide an important toolbox for analyzing terrestrial vegetation structure and associated plant biomass across different scales. At the global and regional scales, spaceborne and airborne LiDAR provide useful biomass estimates across large geographic areas. At the local scale, terrestrial laser scanning (TLS) provides highly detailed information of structural vegetation parameters. Nonetheless, both methods might lack crucial information on other spatially variable parameters, as tree allometry and maximum height are altered by environmental conditions, affecting forest structure and wood density [38]. Because each of the methods and evaluated vegetation parameters may be associated with measurement errors, it is crucial to evaluate systematic, random, and cumulative errors that could propagate to large uncertainties when incorporated into general biomass equations $[1,3,71]$. In this study, we evaluate relative sources and magnitudes of uncertainty associated with measurements obtained from traditional forest inventory and remote sensing techniques and report the respective error metrics for commonly surveyed vegetation parameters in order to derive tropical biomass estimates.

\subsection{Performance of Laser-Based Electronic Devices for Analyzing Horizontal Vegetation Structure}

In general, the difference between tape measurements and caliper measurements increases with tree size as the non-circularity of trunks is more pronounced for large trees with large diameters (Figure 5, Table 1). Hence, a systematic underestimation of measurements obtained with a caliper compared to a diameter tape has been reported for temperate forests [72-74] as well as tropical forests [75]. The explanation given is that any deviation from the true circular shape of a given tree trunk will increase the ratio of circumference to area according to the magnitude of the deviation of the circular shape of the perimeter. This implies that irregularly shaped trees, if measured with a diameter tape, will report larger diameters than would be obtained by doing perpendicular stem measurements with a caliper [73]. Interestingly, estimates of stem circumference extracted from the LiDAR point cloud showed the same trend as estimates obtained with an electronic caliper (Figure 5). Because the resulting error for the DBH estimates is related to the correct fit of the circle to the tree trunk, both methods underestimated DBH due to a higher systematic error compared to traditional inventory measurements using a diameter tape (Table 1). However, while the systematic error of the caliper was related to irregularities of the tree stem, the greater random error of the TLS was related to the effect of occlusion by vegetation present in the scanning zone and, therefore, related to the identification of a geometric form when extracting tree circumference from the point cloud $[24,28,32,34,46]$. This might 
have led to the observed increasing measurement errors with larger tree diameters (Figure 5), which also corresponded to a greater systematic error and a slight underestimation of DBH with increasing tree size (Table 1). Interestingly, DBH measurements obtained with the electronic caliper showed less total and random error than conventional tape measurements but a higher systematic error due to a slight underestimation of DBH in the large size classes (Figure 5). Accordingly, Calders et al. reported that in contrast to traditional methods, where measurement error typically increases exponentially with increasing DBH, novel laser-based techniques are not dependent on DBH, as TLS does not rely on indirect relationships with tree parameters or calibration data and, therefore, showed better agreement with the reference data [46]. Nonetheless, associated parameters will be biased if not based on the same sample size, i.e., number of tree stems within a given diameter inclusion limit (often DBH $\geq 10 \mathrm{~cm}$ ), and thus, typically extracted attributes, such as stem volume (Figure A1) and basal area (Figure A2), are related to the number of individual tree stems recorded [76,77]. Hence, a direct comparison among studies using different methodologies is often hindered by the fact that measurement uncertainties are based on different numbers of individuals investigated, as well as different errors metrics obtained by respective method.

\subsection{Performance of Laser-Based Electronic Devices for Analyzing Vertical Vegetation Structure}

Although it has been suggested that it is not feasible to accurately estimate tree height (Ht) in natural forests from the ground-level $[55,78]$, our results suggest that laser-based electronic devices can and should be used to estimate $\mathrm{Ht}$ in natural forests $[46,56,79,80]$. For traditional inventories, tree climbing is often used to characterize vegetation structure in tropical forests [55,81,82], which typically results in an underestimation of total tree height as even a professional tree climber cannot easily reach the very top of a given tree. In contrast, we found that estimates obtained from laser-based electronic devices tend to overestimate Ht when compared to traditional forest inventory measurements (Figure 7). Such a discrepancy between in situ measurements and remotely sensed estimates typically results from the fact that measurements based on trigonometry usually overestimate total Ht because the apex of a tree crown cannot be spotted from the ground by the observer [55]. Therefore, the accuracy of height estimates in tropical forests has been shown to highly depend on the measurement method applied (i.e., tangent vs. sine method) and experience among different operators [55] because the laser beam, in fact, hits the outer edge of the tree crown, which increases the vertical angle and systematically overestimates Ht. Hence, a direct comparison between laser-based estimates and vertical tape measurements is hindered by differences in error metrics. While random errors are typically associated with statistical variability due to the reproducibility of the measurement (i.e., precision), systematic errors typically refer to a statistical bias between a result and a "true" value (i.e., accuracy). In this regard, methods assessing $\mathrm{Ht}$ presented in this study showed a relatively high precision but not necessarily a high accuracy compared to traditional measurement techniques found in the literature $[56,80,83]$. However, as a high accuracy requires both high precision and high trueness, both methods may only be outperformed by destructively harvesting and measuring felled trees, which is laborious and time consuming. Nevertheless, laser-based technologies have been recently used to create locally derived height-diameter relationships, which was shown to result in improved allometric equations estimating aboveground biomass for specific geographic regions [84].

So far, most studies comparing height estimates with TLS have been conducted in temperate regions and reported that TLS estimates were better predictors for Ht compared to estimates based on trigonometry with a hypsometer [46]. For tropical regions, estimates of Ht obtained via TLS have usually been compared to estimates obtained from trigonometric techniques $[28,31,85,86]$, which present measurement uncertainties of 0.1 to $7.9 \mathrm{~m}$ depending on the method and characteristics of the site [62,87-89]. A more robust analysis of natural eucalyptus forest by Calders et al. [46] compared laser-based estimates of $\mathrm{Ht}$ to measurements from trees felled after completing the scan, and the associated error metrics showed that TLS estimates were actually more accurate than conventional methods (RMSE 0.55 and $1.28 \mathrm{~m}$, for TLS and LR respectively). This highlights that 
direct and individual measurements are extremely important for the calibration and validation of remotely sensed vegetation parameters, such as those obtained from airborne LiDAR [90-93] and spaceborne LiDAR [15,94-96]. In particular, terrestrial LiDAR has been highlighted as a promising tool replacing destructive sampling methods $[97,98]$, as local plot-level measurements can be used for the calibration and validation of indirectly assessed allometric relationships to estimate aboveground plant biomass [2]. Furthermore, TLS can derive many more relevant ecological vegetation metrics not commonly assessed by other methods, such as leaf area index, gap fraction, leaf and branch volume, canopy architecture, planar projection, volume, and habitat characterization for fauna or detailed ecophysiological modelling $[20,44,63,99]$. Nevertheless, each of the estimated parameters will be subject to measurement errors, such that it is crucial to evaluate cumulative errors that could propagate to large uncertainties when incorporated into biomass models $[1,41,94]$. This calls for studies that determine respective error metrics by comparing multiple methodological techniques at the plot-scale in order to identify relative sources and magnitudes of measurement uncertainties associated with respective method applied in situ [2].

\subsection{Performance of Laser-Based Electronic Devices for Estimating Forest Biomass}

Tropical AGB varies across geographic regions in association with the diameter-height relationship among tropical regions, such that Asian forests although exhibiting higher biomass were underestimated globally due to higher-than-average tree height observed in palaeotropical forests [5]. Due to high variation of allometrical DBH:Ht relationships within tropical forests $[6,100]$, conducting $\mathrm{Ht}$ measurements at the local level is of fundamental importance to improve estimates of aboveground biomass [4,10]. For instance, to overcome chronic underestimation of AGB of very large trees, some studies derived local diameter-height allometric models in areas where trees are shorter but have large crowns [70]. However, it has been recently suggested that a relatively simple procedure would be to identify the ten largest diameter trees in a plot for measurements of total height and then take a diameter size-class stratified random sample of an additional forty trees to build a local DBH:Ht model that minimizes uncertainty in estimates of aboveground biomass [84]. Hence, the instruments investigated in this study could and should be used to survey Ht locally in a practical and economically viable way.

We furthermore assessed several commonly applied allometric equations to estimate AGB, as some of the differences in biomass estimates might be related to differences in parameterization among allometric equations. For instance, the pantropical equations by Feldpausch et al. [5] and Chave et al. [10] are based on a database compiled from trees felled in the tropics around the world, thus containing trees from different climatic, edaphic, and resource availability gradients $[6,7,10,101-103]$. Even over continental-wide gradients, such as across the Amazon basin, applying adjusted equations for central Amazonia was reported to result in a high bias when estimating tree biomass in the south and southwest of the Amazon [101]. While this was mainly due to differences in wood density [102] and DBH:Ht ratios [91], other studies reported that the use of metrics related to crown volume reduces uncertainties for areas where trees are small statured but have large crowns [70]. This high variation of environmental conditions affecting forest structure among tropical regions implies that local allometries based on locally felled trees and quantifying the biomass of different compartments of the tree [69] are expected to better capture local vegetation characteristics than more general pantropical equations [10].

Hence, in this study, we considered the local allometric equation as the local reference estimate [69]. Compared to the local reference equation (including DBH and $\mathrm{Ht}$ ), the local diameter-only equation [69], as well as the pantropical equations [5,10], overestimated the aboveground biomass regardless of the technology used (Figure 8). Although both of the pantropical equations were derived from felled trees harvested from forest communities across different tropical regions, the local estimates excluding tree height were still closer to the reference estimate (including DBH and $\mathrm{Ht}$ ). Surprisingly, in three out of four allometric equations tested, we found an underestimation of biomass by the laser-based electronic devices tested in this study in comparison with conventional measurements 
(Figure 8). Nonetheless, in comparison TLS-based estimates (TLS) showed a slightly better performance than that based on measurements obtained with the electronic caliper and hypsometer (FM), such that biomass was overestimated by $8.4 \%$ and $6.7 \%$ by FM and TLS respectively (Figure A3). Whereas laser-based techniques on average overestimated AGB by 16.5\% and 18.2\% for FM and TLS caused by a systematic overestimation of tree height compared to conventional tape measurements, AGB was underestimated by $4.3 \%$ and $2.1 \%$ for FM and TLS because of a systematic underestimation of tree diameters with increasing tree size class. Hence, our findings of inverse effects on biomass estimates due to error metrics derived from measurements based on DBH and/or Ht should be of importance for analysis of large-scale AGB estimates derived from remote sensing, particularly applications mapping the forest canopy height to derive biomass estimates across large spatial areas.

These nondestructive techniques represent a powerful alternative to destructive tree felling and can be used to estimate the biomass of large trees to within a few percent [2-4,44,97]. Recently, studies on native forests of subtropical [46] and tropical climate [11,47] showed that TLS-based AGB estimates were able to estimate the biomass of trees without bias and with shape accuracy when compared to local allometric equations. This finding might be crucial as large-diameter trees $(\mathrm{DBH}>60 \mathrm{~cm})$ are usually especially prone to measurement errors [104] but concomitantly represent large parts of the forest ecosystem carbon budget by constituting half of the forest biomass worldwide [105]. Hence, the propagation of measurement errors might introduce some uncertainty to the biomass estimate of a particular site, especially if one single method is used to calibrate products from another platform, e.g., spaceborne and airborne LIDAR, such that local uncertainty could potentially propagate to larger areas. Overall, we conclude that it is crucial to combine several measurement techniques to improve potential mismatches among pantropical allometric equations and local observations. Eventually, further refined novel technologies will represent a valuable alternative to destructive conventional sampling techniques, which should allow assessing the response of tropical plant biomass to projected alterations in climatic signals.

\section{Conclusions}

Based on the results presented in this study, we conclude that laser-based electronic devices have the potential to estimate tree size parameters commonly surveyed by traditional forest inventories. The presented novel techniques exhibited error metrics comparable with traditional methods and differences between respective devices were related to technical attributes of each instrument. Whereas, estimates of horizontal vegetation structure, i.e., tree diameters obtained from the point cloud exhibited relatively high total $(11.1 \%)$ and random errors $(11.0 \%)$ compared to measurements taken with a diameter tape, perpendicular measurements with an electronic caliper were more consistent but resulted in systematic underestimation $(-2.3 \%)$ of individual tree diameters. For vertical vegetation structure, the estimates of tree height based on hypsometer-triangulation gave better results than previously reported $(11.7 \%)$, while the estimates based on point cloud extraction yielded more consistent results $(10.1 \%)$ in comparison to vertical tape measurements. Albeit that laser-based techniques systematically overestimated stand aboveground biomass (by $26.6 \%$ to $31.0 \%$ ), this was due to a relatively high precision $(-2.5 \%)$ within methods but a low accuracy $(26.8-31.2 \%)$ among predicted and observed values. Most strikingly, the variation of estimated aboveground biomass was larger among commonly applied allometries (39.7-66.4\%) than between traditional and novel measurement techniques (10.6-15.0\%). This indicates that locally derived estimates based on relatively low sample size ( $<50$ individual stems) could be used to construct local height-diameter relationships with lower error than regional or climate-based allometries. We therefore conclude that laser-based electronic devices can and should be used to complement traditional forest inventories for monitoring structural vegetation parameters in tropical forests. 
Author Contributions: The following statements specify the respective authors' individual contributions. Writing-original draft preparation, I.S.P. and F.H.; conceptualization I.S.P., H.E.M.d.N., and F.H.; methodology, I.S.P. and H.E.M.d.N.; software, M.B.V.; validation, M.D.; formal analysis, I.S.P.; investigation, I.S.P.; resources, M.D.; data curation, M.D.; visualization, I.S.P., M.B.V., and M.D.; supervision, H.E.M.d.N. and C.A.Q.; project administration, C.A.Q. and D.L.; funding acquisition, D.L.; writing-review and editing, all co-authors.

Funding: We thank the anonymous reviewers for their helpful suggestions and comments on the manuscript. The AmazonFACE program provided logistical support to conduct this study. The AmazonFACE program is funded by the Inter-American Development Bank through a technical cooperation agreement with the Brazilian Ministry of Science, Technology, Innovation and Communications (Grant BR-T1284); by Brazil's Coordination for the Improvement of Higher Education Personnel (CAPES) Grant 23038.007722/2014-77; and by Amazonas Research Foundation (FAPEAM) Grant 2649/2014.

Acknowledgments: We are obliged to several persons that enabled our research stay at ZF2. We thank Bruno Takeshi, Ana Paula Rocha, and Luciano Castilho for providing logistic support as well as all volunteer researchers who helped during the fieldwork and setup of the experiment. We thank Alacimar Guedes by the quality in the service of climbing the trees. Finally, we appreciate the helpful comments provided by the reviewers of this paper whose corrections have led to an improvement of the text.

Conflicts of Interest: The authors declare no conflict of interest.

\section{Appendix A}

Table A1. The equations for estimating the aboveground biomass (in $\mathrm{kg}$ ) with diameter ( $\mathrm{D}$ in $\mathrm{cm}$ ), total height ( $\mathrm{Ht}$ in $\mathrm{m})$, and wood density $\left(\rho\right.$ in $\left.\mathrm{g} / \mathrm{cm}^{3}\right)$.

\begin{tabular}{cccc}
\hline Regions & $\begin{array}{c}\text { Diameter Interval } \\
\text { (cm) }\end{array}$ & Equations & References \\
\hline Central & $5 \leq \mathrm{D} \leq 20$ & $\mathrm{Ln}(\mathrm{W})=-1.754+2.665 \ln \mathrm{D}^{*}$ & Higuchi et al. 1998 \\
Amazon & $\mathrm{D} \geq 20$ & $\mathrm{Ln}(\mathrm{W})=-0.151+2.170 \ln \mathrm{D}^{*}$ & \\
Central & $5 \leq \mathrm{D} \leq 20$ & $\mathrm{~W}=0.0336^{*} \mathrm{D}^{2.171} \mathrm{Ht}^{1.038 * *}$ & Higuchi et al. 1998 \\
Amazon & $\mathrm{D} \geq 20$ & $\mathrm{~W}=0.0009^{*} \mathrm{D}^{1.585} \mathrm{Ht}^{2.651 * *}$ & Chave et al. 2014 \\
Pantropical & $\mathrm{D} \geq 5$ & $\mathrm{AGB}=0.0673^{*}\left(\rho \mathrm{D}^{2} \mathrm{Ht}\right)^{0.976}$ & Feldpausch et al. 2012 \\
Pantropical & $\mathrm{D} \geq 10$ & $\mathrm{Ln}(\mathrm{AGB})=-2.9205+$ & $0.9894 \ln \left(\mathrm{D}^{2} \rho \mathrm{Ht}\right)$
\end{tabular}

* The equations from Higuchi et al. 1998 directly estimate dry biomass based on field measurements of destructively harvested "fresh biomass" (W) and apply a correction factor of 0.6028 [70]. ** The equation used as a reference for calculating the errors in biomass estimates among the equations evaluated.
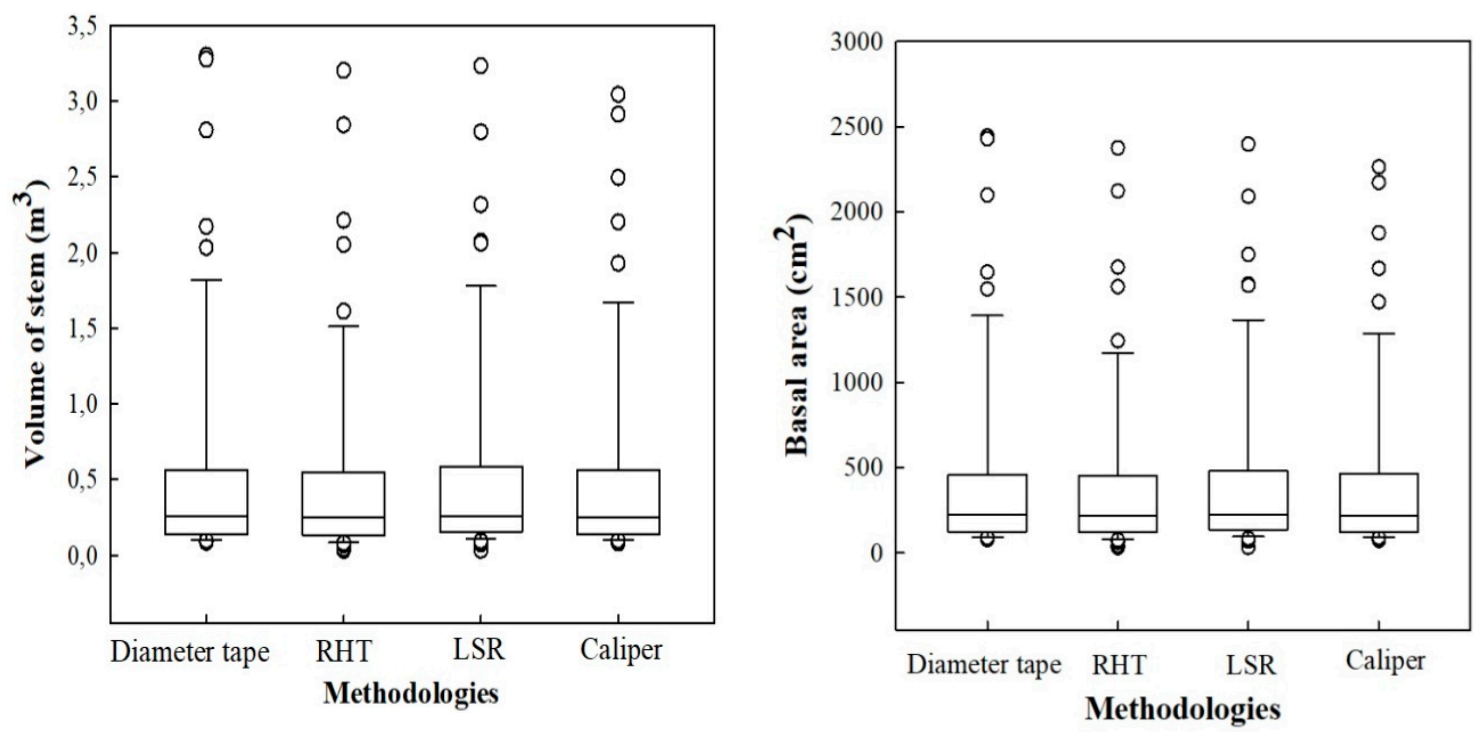

Figure A1. The volume of the stem $\left(\mathrm{V}_{\text {stem }}\right)$ using the formula $(\ln \mathrm{V}=-7.335+2.121 \ln \mathrm{DBH})$ proposed by Higuchi et al. (1997) and the basal area for the respective methodologies, i.e., diameter tape (Diameter tape), TLS $_{\text {RHT }}(\mathrm{RHT}), \mathrm{TLS}_{\mathrm{LSR}}$ (LSR), and electronic caliper (Caliper), used to estimate the plot-level parameters for trees $(\mathrm{DBH} \geq 10 \mathrm{~cm})$. 


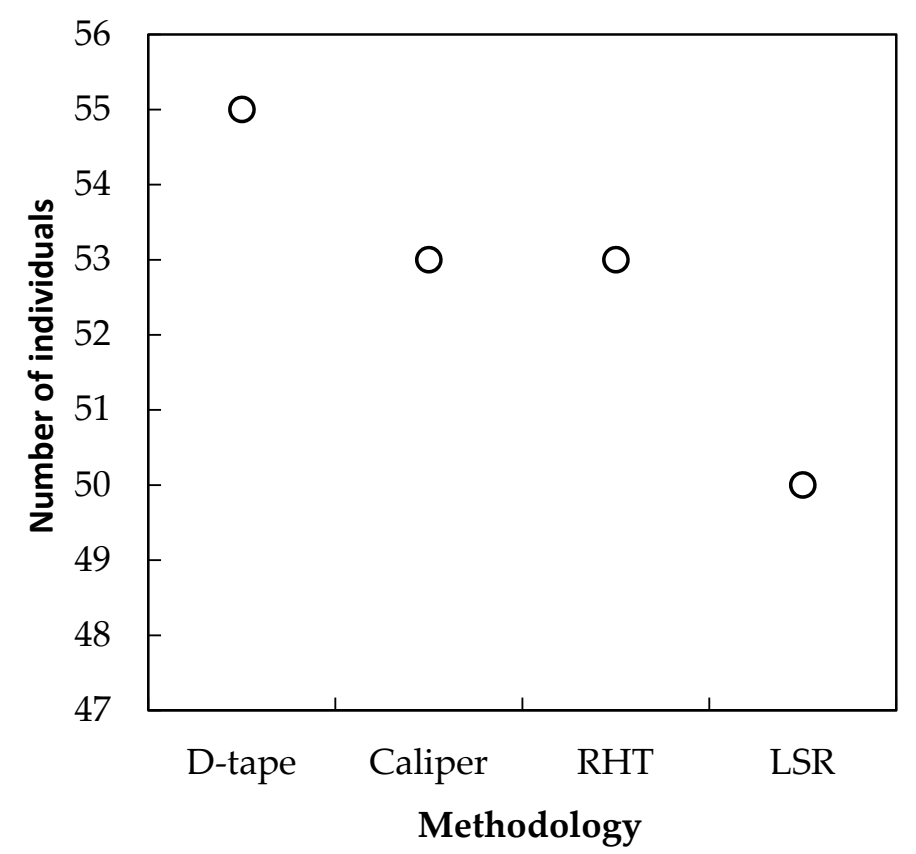

Figure A2. The number of individuals identified within the diameter inclusion limit (DBH $\geq 10 \mathrm{~cm})$ for respective methodology applied, i.e., diameter tape (D-tape), electronic caliper (Caliper), terrestrial laser scanner circle fitted via Hough transformation (RHT), and least-squares method (LSR).

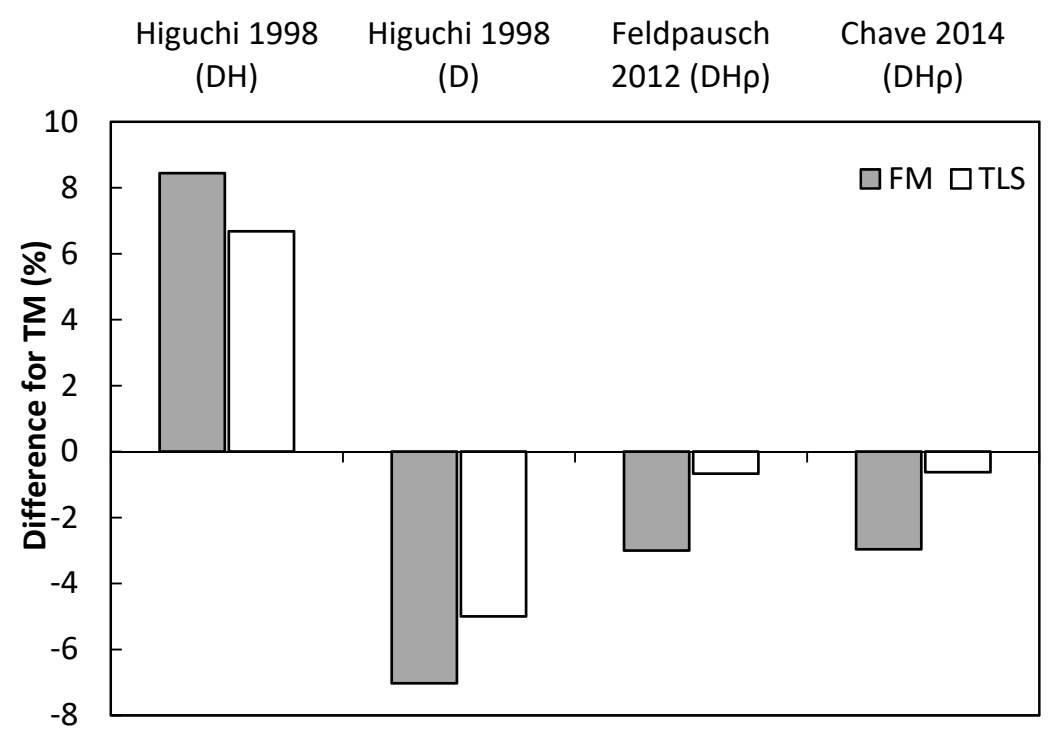

Figure A3. The difference among estimates of the total aboveground biomass using data obtained from tape measurements (TM) vs. Fieldmap bundle (FM) or terrestrial laser scanner (TLS) and respective allometric equations (listed in Table A1).

\section{References}

1. Saatchi, S.S.; Harris, N.L.; Brown, S.; Lefsky, M.; Mitchard, E.T.A.; Salas, W.; Zutta, B.R.; Buermann, W.; Lewis, S.L.; Hagen, S.; et al. Benchmark map of forest carbon stocks in tropical regions across three continents. Proc. Natl. Acad. Sci. USA 2011, 108, 9899-9904. [CrossRef] [PubMed]

2. Mitchard, E.T.A.; Feldpausch, T.R.; Brienen, R.J.W.; Lopez-Gonzalez, G.; Monteagudo, A.; Baker, T.R.; Lewis, S.L.; Lloyd, J.; Quesada, C.A.; Gloor, M.; et al. Markedly divergent estimates of Amazon forest carbon density from ground plots and satellites. Glob. Ecol. Biogeogr. 2014, 23, 935-946. [CrossRef] [PubMed] 
3. Ometto, J.P.; Aguiar, A.P.; Assis, T.; Soler, L.; Valle, P.; Tejada, G.; Lapola, D.M.; Meir, P. Amazon forest biomass density maps: Tackling the uncertainty in carbon emission estimates. Clim. Chang. 2014, 124, 545-560. [CrossRef]

4. Chave, J.; Andalo, C.; Brown, S.; Cairns, M.A.; Chambers, J.Q.; Eamus, D.; Fölster, H.; Fromard, F.; Higuchi, N.; Kira, T.; et al. Tree allometry and improved estimation of carbon stocks and balance in tropical forests. Oecologia 2005, 145, 87-99. [CrossRef] [PubMed]

5. Feldpausch, T.R.; Lloyd, J.; Lewis, S.L.; Brienen, R.J.W.; Gloor, M.; Monteagudo Mendoza, A.; Lopez-Gonzalez, G.; Banin, L.; Abu Salim, K.; Affum-Baffoe, K.; et al. Tree height integrated into pantropical forest biomass estimates. Biogeosciences 2012, 9, 3381-3403. [CrossRef]

6. Feldpausch, T.R.; Banin, L.; Phillips, O.L.; Baker, T.R.; Lewis, S.L.; Quesada, C.A.; Affum-Baffoe, K.; Arets, E.J.M.M.; Berry, N.J.; Bird, M.; et al. Height-diameter allometry of tropical forest trees. Biogeosciences 2011, 8, 1081-1106. [CrossRef]

7. Banin, L.; Feldpausch, T.R.; Phillips, O.L.; Baker, T.R.; Lloyd, J.; Affum-Baffoe, K.; Arets, E.J.M.M.; Berry, N.J.; Bradford, M.; Brienen, R.J.W.; et al. What controls tropical forest architecture? Testing environmental, structural and floristic drivers. Glob. Ecol. Biogeogr. 2012, 21, 1179-1190. [CrossRef]

8. Ploton, P.; Barbier, N.; Takoudjou Momo, S.; Réjou-Méchain, M.; Boyemba Bosela, F.; Chuyong, G.; Dauby, G.; Droissart, V.; Fayolle, A.; Goodman, R.C.; et al. Closing a gap in tropical forest biomass estimation: Taking crown mass variation into account in pantropical allometries. Biogeosciences 2016, 13, 1571-1585. [CrossRef]

9. Chave, J.; Condit, R.; Aguilar, S.; Hernandez, A.; Lao, S.; Perez, R. Error propagation and scaling for tropical forest biomass estimates. Philos. Trans. R. Soc. B Biol. Sci. 2004, 359, 409-420. [CrossRef] [PubMed]

10. Chave, J.; Réjou-Méchain, M.; Búrquez, A.; Chidumayo, E.; Colgan, M.S.; Delitti, W.B.C.; Duque, A.; Eid, T.; Fearnside, P.M.; Goodman, R.C.; et al. Improved allometric models to estimate the aboveground biomass of tropical trees. Glob. Chang. Biol. 2014, 20, 3177-3190. [CrossRef] [PubMed]

11. Momo Takoudjou, S.; Ploton, P.; Sonké, B.; Hackenberg, J.; Griffon, S.; de Coligny, F.; Kamdem, N.G.; Libalah, M.; Mofack, G.I.; Le Moguédec, G.; et al. Using terrestrial laser scanning data to estimate large tropical trees biomass and calibrate allometric models: A comparison with traditional destructive approach. Methods Ecol. Evol. 2018, 9, 905-916. [CrossRef]

12. Dassot, M.; Constant, T.; Fournier, M. The use of terrestrial LiDAR technology in forest science: Application fields, benefits and challenges. Ann. For. Sci. 2011, 68, 959-974. [CrossRef]

13. Newnham, G.J.; Armston, J.D.; Calders, K.; Disney, M.I.; Lovell, J.L.; Schaaf, C.B.; Strahler, A.H.; Danson, F.M. Terrestrial Laser Scanning for Plot-Scale Forest Measurement. Curr. For. Rep. 2015, 1, 239-251. [CrossRef]

14. Lefsky, M.A. A global forest canopy height map from the moderate resolution imaging spectroradiometer and the geoscience laser altimeter system. Geophys. Res. Lett. 2010, 37, 1-5. [CrossRef]

15. Hu, T.; Su, Y.; Xue, B.; Liu, J.; Zhao, X.; Fang, J.; Guo, Q. Mapping global forest aboveground biomass with spaceborne LiDAR, optical imagery, and forest inventory data. Remote Sens. 2016, 8, 565. [CrossRef]

16. Bouvet, A.; Mermoz, S.; Le Toan, T.; Villard, L.; Mathieu, R.; Naidoo, L.; Asner, G.P. An above-ground biomass map of African savannahs and woodlands at $25 \mathrm{~m}$ resolution derived from ALOS PALSAR. Remote Sens. Environ. 2018, 206, 156-173. [CrossRef]

17. Asner, G.P.; Knapp, D.E.; Martin, R.E.; Tupayachi, R.; Anderson, C.B.; Mascaro, J.; Sinca, F.; Chadwick, K.D.; Higgins, M.; Farfan, W.; et al. Targeted carbon conservation at national scales with high-resolution monitoring. Proc. Natl. Acad. Sci. USA 2014, 111, E5016-E5022. [CrossRef] [PubMed]

18. Dittmann, S.; Thiessen, E.; Hartung, E. Applicability of different non-invasive methods for tree mass estimation: A review. For. Ecol. Manag. 2017, 398, 208-215. [CrossRef]

19. Åkerblom, M.; Raumonen, P.; Mäkipää, R.; Kaasalainen, M. Automatic tree species recognition with quantitative structure models. Remote Sens. Environ. 2017, 191, 1-12. [CrossRef]

20. Hackenberg, J.; Spiecker, H.; Calders, K.; Disney, M.; Raumonen, P. SimpleTree-An efficient open source tool to build tree models from TLS clouds. Forests 2015, 6, 4245-4294. [CrossRef]

21. Liang, X.; Kankare, V.; Hyyppä, J.; Wang, Y.; Kukko, A.; Haggrén, H.; Yu, X.; Kaartinen, H.; Jaakkola, A.; Guan, F.; et al. Terrestrial laser scanning in forest inventories. ISPRS J. Photogramm. Remote Sens. 2016, 115, 63-77. [CrossRef] 
22. Wang, N.; Shen, Y.; Hua, J.; Wang, H.; Kang, M.; Su, X. Analyzing the canopy light distribution among different poplar genotypes using terrestrial laser scanner and the GreenLab model. In Proceedings of the 2016 IEEE International Conference on Functional-Structural Plant Growth Modeling, Simulation, Visualization and Applications (FSPMA), Qingdao, China, 7-11 November 2016; pp. 214-223.

23. Calders, K.; Schenkels, T.; Bartholomeus, H.; Armston, J.; Verbesselt, J.; Herold, M. Monitoring spring phenology with high temporal resolution terrestrial LiDAR measurements. Agric. For. Meteorol. 2015, 203, 158-168. [CrossRef]

24. Yang, X.; Strahler, A.H.; Schaaf, C.B.; Jupp, D.L.B.; Yao, T.; Zhao, F.; Wang, Z.; Culvenor, D.S.; Newnham, G.J.; Lovell, J.L.; et al. Three-dimensional forest reconstruction and structural parameter retrievals using a terrestrial full-waveform lidar instrument (Echidna ${ }^{\circledR}$ ). Remote Sens. Environ. 2013, 135, 36-51. [CrossRef]

25. Krooks, A.; Kaasalainen, S.; Kankare, V.; Joensuu, M.; Raumonen, P.; Kaasalainen, M. Tree structure vs. height from terrestrial laser scanning and quantitative structure models. Silva Fenn. 2014, 48, 1-11. [CrossRef]

26. Raumonen, P.; Casella, E.; Calders, K.; Murphy, S.; Åkerbloma, M.; Kaasalainen, M. Massive-scale tree modelling from tls data. ISPRS Ann. Photogramm. Remote Sens. Spat. Inf. Sci. 2015, II-3/W4, 189-196. [CrossRef]

27. Lau Sarmiento, A.I.; Bartholomeus, H.; Herold, M.; Martius, C.; Malhi, Y.; Patrick Bentley, L.; Shenkin, A.; Raumonen, P. Application of terrestrial LiDAR and modelling of tree branching structure for plantscaling models in tropical forest trees. In Proceedings of the 14th Conference on Lidar Applications for Assessing and Managing Forest Ecosystems, La Grande Motte, France, 28-30 September 2015; pp. 96-98.

28. Rahman, M.Z.; Bakar, M.A.A.; Razak, K.A.; Rasib, A.W.; Kanniah, K.D.; Kadir, W.H.W.; Omar, H.; Faidi, A.; Kassim, A.R.; Latif, Z.A. Non-Destructive, Laser-Based Individual Tree Aboveground Biomass Estimation in a Tropical Rainforest. Forests 2017, 8, 86. [CrossRef]

29. Rahman, M.Z.; Majid, Z.; Bakar, M.A.A.; Kadir, W.H.W. Individual tree measurement in tropical environment using terrestrial laser scanning. J. Teknol. 2015, 73, 127-133. [CrossRef]

30. Olagoke, A.; Proisy, C.; Féret, J.B.; Blanchard, E.; Fromard, F.; Mehlig, U.; de Menezes, M.M.; dos Santos, V.F.; Berger, U. Extended biomass allometric equations for large mangrove trees from terrestrial LiDAR data. Trees Struct. Funct. 2016, 30, 935-947. [CrossRef]

31. Palace, M.; Sullivan, F.B.; Ducey, M.; Herrick, C. Estimating Tropical Forest Structure Using a Terrestrial Lidar. PLoS ONE 2016, 11, e0154115. [CrossRef] [PubMed]

32. Lovell, J.L.; Jupp, D.L.B.; Newnham, G.J.; Culvenor, D.S. Measuring tree stem diameters using intensity profiles from ground-based scanning lidar from a fixed viewpoint. ISPRS J. Photogramm. Remote Sens. 2011, 66, 46-55. [CrossRef]

33. Lovell, J.L.; Jupp, D.L.B.; Culvenor, D.S.; Coops, N.C. Using airborne and ground-based ranging lidar to measure canopy structure in Australian forests. Can. J. Remote Sens. 2003, 29, 607-622. [CrossRef]

34. Strahler, A.H.; Jupp, D.L.; Woodcock, C.E.; Schaaf, C.B.; Yao, T.; Zhao, F.; Yang, X.; Lovell, J.; Culvenor, D.; Newnham, G.; et al. Retrieval of forest structural parameters using a ground-based lidar instrument (Echidna ${ }^{\circledR}$ ). Can. J. Remote Sens. 2008, 34, S426-S440. [CrossRef]

35. Yao, T.; Yang, X.; Zhao, F.; Wang, Z.; Zhang, Q.; Jupp, D.; Lovell, J.; Culvenor, D.; Newnham, G.; Ni-Meister, W.; et al. Measuring forest structure and biomass in New England forest stands using Echidna ground-based lidar. Remote Sens. Environ. 2011, 115, 2965-2974. [CrossRef]

36. Condit, R. Tropical Forest Census Plots; Springer: Berlin/Heidelberg, Germany, 1998; ISBN 978-3-662-03666-2.

37. Rovero, F.; Ahumada, J. The Tropical Ecology, Assessment and Monitoring (TEAM) Network: An early warning system for tropical rain forests. Sci. Total Environ. 2017, 574, 914-923. [CrossRef] [PubMed]

38. Marthews, T.R.; Riutta, T.; Oliveras Menor, I.; Urrutia, R.; Moore, S.; Metcalfe, D.; Malhi, Y.; Phillips, O.; Huaraca Huasco, W.; Ruiz Jaén, M.; et al. Measuring Tropical Forest Carbon Allocation and Cycling: A RAINFOR-GEM Field Manual for Intensive Census Plots (v3.0). Manual, Global Ecosystems Monitoring Network. 2014. Available online: http:/ /gem.tropicalforests.ox.ac.uk/ (accessed on 5 February 2018).

39. Anderson-Teixeira, K.J.; Davies, S.J.; Bennett, A.C.; Gonzalez-Akre, E.B.; Muller-Landau, H.C.; Joseph Wright, S.; Abu Salim, K.; Almeyda Zambrano, A.M.; Alonso, A.; Baltzer, J.L.; et al. CTFS-ForestGEO: A worldwide network monitoring forests in an era of global change. Glob. Chang. Biol. 2015, 21, 528-549. [CrossRef] [PubMed] 
40. Phillips, O.; Baker, T.; Feldpausch, T.; Brienen, R. Field Manual for Establishment and Remeasurement (RAINFOR). Available online: http:/ / www.rainfor.org/upload/ManualsEnglish/RAINFOR_field_manual_ version_2016.pdf (accessed on 5 February 2018).

41. van Laar, A.; Akça, A. Forest Mensuration, 2nd ed.; Managing Forest Ecosystems; Springer: Dordrecht, The Netherlands, 2007; Volume 13, ISBN 978-1-4020-5990-2.

42. Wilkes, P.; Lau, A.; Disney, M.; Calders, K.; Burt, A.; Gonzalez de Tanago, J.; Bartholomeus, H.; Brede, B.; Herold, M. Data acquisition considerations for Terrestrial Laser Scanning of forest plots. Remote Sens. Environ. 2017, 196, 140-153. [CrossRef]

43. Burt, A.; Disney, M.; Calders, K. Extracting individual trees from lidar point clouds using treeseg. Methods Ecol. Evol. 2018. [CrossRef]

44. Meir, P.; Shenkin, A.; Disney, M.; Rowland, L.; Malhi, Y.; Herold, M.; da Costa, A.C.L. Plant structure-function relationships and woody tissue respiration: Upscaling to forests from laser-derived measurements. In Plant Respiration: Metabolic Fluxes and Carbon Balance; Tcherkez, G., Ghashghaie, J., Eds.; Springer: Dordrecht, The Netherlands, 2017; ISBN 9783319687032.

45. Tavares, G.G.; Sabino, T.L.R.; da Fonseca, L.G. Métodos computacionais para aproximação do diâmetro à altura do peito de árvores de regiões de mangue via escaneamento tridimensional a laser. Rev. Interdiscip. Pesqui. em Eng. 2016, 2, 138-155.

46. Calders, K.; Newnham, G.; Burt, A.; Murphy, S.; Raumonen, P.; Herold, M.; Culvenor, D.; Avitabile, V.; Disney, M.; Armston, J.; et al. Nondestructive estimates of above-ground biomass using terrestrial laser scanning. Methods Ecol. Evol. 2015, 6, 198-208. [CrossRef]

47. De Tanago, J.G.; Lau, A.; Bartholomeusm, H.; Herold, M.; Avitabile, V.; Raumonen, P.; Martius, C.; Goodman, R.; Disney, M.; Manuri, S.; et al. Estimation of above-ground biomass of large tropical trees with Terrestrial LiDAR. Methods Ecol. Evol. 2017, 2017, 1-12. [CrossRef]

48. Peel, M.C.; Finlayson, B.L.; McMahon, T.A. Updated world map of the Köppen-Geiger climate classification. Hydrol. Earth Syst. Sci. Discuss. 2007, 4, 439-473. [CrossRef]

49. Araújo, A.C.; Nobre, A.D.; Kruijt, B.; Elbers, J.A.; Dallarosa, R.; Stefani, P.; Von Randow, C.; Manzi, A.O.; Culf, A.D.; Gash, J.H.C.; et al. Comparative measurements of carbon dioxide fluxes from two nearby towers in a central Amazonian rainforest: The Manaus LBA site. J. Geophys. Res. 2002, 107, 1-20. [CrossRef]

50. Luizão, R.C.C.; Luizão, F.J.; Paiva, R.Q.; Monteiro, T.F.; Sousa, L.S.; Kruijt, B. Variation of carbon and nitrogen cycling processes along a topographic gradient in a central Amazonian forest. Glob. Chang. Biol. 2004, 10, 592-600. [CrossRef]

51. IBGE. Manual Técnico da Vegetação Brasileira; IBGE: Rio de Janeiro, Brazil, 2012; ISBN 9788524042720.

52. Vieira, S.; de Camargo, P.B.; Selhorst, D.; da Silva, R.; Hutyra, L.; Chambers, J.Q.; Brown, I.F.; Higuchi, N.; dos Santos, J.; Wofsy, S.C.; et al. Forest structure and carbon dynamics in Amazonian tropical rain forests. Oecologia 2004, 140, 468-479. [CrossRef] [PubMed]

53. Carneiro, V.M.C.; Higuchi, N.; Dos Santos, J.; Pinto, A.C.M.; Teixeira, L.M.; Lima, A.J.N.; Da Silva, R.P.; Rocha, R.M. Composição florística e análise estrutural da floresta de terra-firme na região de Manaus, estado do Amazonas, Brasil. In Proceedings of the $5^{\circ}$ Congresso Florestal Nacional-A Floresta e as Gentes, Viseu, Portugal, 16-19 May 2005.

54. Clark, D.A.; Brown, S.; Kicklighter, D.W.; Chambers, J.Q.; Thomlinson, J.R.; Ni, J. Measuring net primary production in forest concepts and field methods. Ecol. Appl. 2001, 11, 356-370. [CrossRef]

55. Feldpausch, T.R.; Banin, L.; Phillips, O.L.; Baker, T.R.; Lewis, S.L.; Quesada, C.A.; Affum-Baffoe, K.; Arets, E.J.M.M.; Berry, N.J.; Bird, M.; et al. Height-diameter allometry of tropical forest trees (Supplemental Information). Biogeosciences 2011, 8, 1081-1106. [CrossRef]

56. Larjavaara, M.; Muller-Landau, H.C. Measuring tree height: A quantitative comparison of two common field methods in a moist tropical forest. Methods Ecol. Evol. 2013, 4, 793-801. [CrossRef]

57. Henning, J.G.; Radtke, P.J. Detailed Stem Measurements of Standing Trees from Ground-Based Scanning Lidar. For. Sci. 2006, 52, 67-80.

58. Hosoi, F.; Omasa, K. Voxel-Based 3-D Modeling of Individual Trees for Estimating Leaf Area Density Using High-Resolution Portable Scanning Lidar. IEEE Trans. Geosci. Remote Sens. 2006, 44, 3610-3618. [CrossRef]

59. Riegl Laser Measurement Systems Riegl Vz-400 Features and Components. Available online: http:/ / www. riegl.com/uploads/tx_pxpriegldownloads/10_DataSheet_VZ-400_2017-06-14.pdf (accessed on 2 March 2019). 
60. Calders, K.; Disney, M.I.; Armston, J.; Burt, A.; Brede, B.; Origo, N.; Muir, J.; Nightingale, J. Evaluation of the Range Accuracy and the Radiometric Calibration of Multiple Terrestrial Laser Scanning Instruments for Data Interoperability. IEEE Trans. Geosci. Remote Sens. 2017, 55, 2716-2724. [CrossRef]

61. Rusu, R.B.; Cousins, S. 3D is here: Point Cloud Library (PCL). In Proceedings of the 2011 IEEE International Conference on Robotics and Automation, Shanghai, China, 9-13 May 2011; pp. 1-4.

62. Hopkinson, C.; Chasmer, L.; Young-Pow, C.; Treitz, P. Assessing forest metrics with a ground-based scanning lidar. Can. J. For. Res. 2004, 34, 573-583. [CrossRef]

63. Trochta, J.; Krůček, M.; Vrška, T.; Král, K. 3D Forest: An application for descriptions of three-dimensional forest structures using terrestrial LiDAR. PLoS ONE 2017, 12, e0176871. [CrossRef] [PubMed]

64. Xu, L.; Oja, E. Randomized Hough Transform (RHT): Basic Mechanisms, Algorithms, and Computational Complexities. CVGIP Image Underst. 1993, 57, 131-154. [CrossRef]

65. Chernov, N.; Lesort, C. Least squares fitting of circles. J. Math. Imaging Vis. 2005, 23, 239-252. [CrossRef]

66. Bohonak, A.J. Software for Reduced Major Axis Regression. 2004. Available online: http:/ /www.bio.sdsu. edu/pub/andy / RMA.html (accessed on 7 February 2019).

67. Walther, B.A.; Moore, J.L. The concepts of bias, precision and accuracy, and their use in testing the performance of species richness estimators, with a literature review of estimator performance. Ecogr. (Cop.) 2005, 28, 815-829. [CrossRef]

68. West, M.J. Stereological methods for estimating the total number of neurons and synapses: Issues of precision and bias. Trends Neurosci. 1999, 22, 51-61. [CrossRef]

69. Higuchi, N.; Dos Santos, J.; Ribeiro, R.J.; Minette, L.; Biot, Y. Biomassa da parte aérea da vegetação da floresta tropical úmida de terra-firme da Amazônia brasileira. Acta Amaz. 1998, 28, 153-166. [CrossRef]

70. Goodman, R.C.; Phillips, O.L.; Baker, T.R. The importance of crown dimensions to improve tropical tree biomass estimates. Ecol. Appl. 2014, 24, 680-698. [CrossRef] [PubMed]

71. Mitchard, E.T.A.; Saatchi, S.S.; Baccini, A.; Asner, G.P.; Goetz, S.J.; Harris, N.L.; Brown, S. Uncertainty in the spatial distribution of tropical forest biomass: A comparison of pan-tropical maps. Carbon Balance Manag. 2013, 8, 1-13. [CrossRef] [PubMed]

72. Behre, E.C. Comparison of diameter tape and caliper measurements in second-growth spruce. J. For. 1926, 24, 178-182.

73. McArdle, R.E. Relative accuracy of calipers and diameter tape in measuring Douglas fir trees. J. For. 1928, 26, 338-342.

74. Binot, J.M.; Pothier, D.; Lebel, J. Comparison of relative accuracy and time requirement between the caliper, the diameter tape and an electronic tree measuring fork. For. Chron. 1995, 71, 197-200. [CrossRef]

75. Clark, N.; Wynne, R.; Schmoldt, D. A review of past research on dendrometers. For. Sci. 2000, 46, 570-576.

76. Condit, R.; Hubbell, S.P.; Lafrankie, J.V.; Sukumar, R.; Manokaran, N.; Foster, R.B.; Ashton, P.S. Species-Area and Species-Individual Relationships for Tropical Trees: A Comparison of Three 50-ha Plots. J. Ecol. 1996, 84, 549. [CrossRef]

77. Condit, R.; Ashton, P.; Baker, P.; Bunyavejchewin, S. Spatial patterns in the distribution of tropical tree species. Science 2000, 288, 1414-1418. [CrossRef] [PubMed]

78. Saatchi, S.S. Interactive comment on "Tree height integrated into pan-tropical forest biomass estimates" by. Biogeosci. Discuss. 2012, 9, C351-C353.

79. Bragg, D.C. The Sine Method as a More Accurate Height Predictor for Hardwoods; e-GTR-SRS-101; U.S. Department of Agriculture, Forest Service, Southern Research Station: Asheville, NC, USA, 2007; pp. 23-32.

80. Hunter, M.O.; Keller, M.; Victoria, D.; Morton, D.C. Tree height and tropical forest biomass estimation. Biogeosciences 2013, 10, 8385-8399. [CrossRef]

81. Gimenez, B.O.; dos Santos, L.T.; Gebara, J.; Celes, C.H.S.; Durgante, F.M.; Lima, A.J.N.; dos Santos, J.; Higuchi, N. Tree Climbing Techniques and Volume Equations for Eschweilera (Matá-Matá), a Hyperdominant Genus in the Amazon Forest. Forests 2017, 8, 154. [CrossRef]

82. Clark, D.A.; Clark, D.B. Getting to the canopy: Tree height growth in a neotropical rain forest. Ecology 2001, 82, 1460-1472. [CrossRef]

83. Bragg, D.C. An Improved Tree Height Measurement Technique Tested on Mature Southern Pines. South. J. Appl. For. 2007, 32, 28-43. 
84. Sullivan, M.J.P.; Lewis, S.L.; Hubau, W.; Qie, L.; Baker, T.R.; Banin, L.F.; Chave, J.; Cuni-Sanchez, A.; Feldpausch, T.R.; Lopez-Gonzalez, G.; et al. Field methods for sampling tree height for tropical forest biomass estimation. Methods Ecol. Evol. 2018, 2018, 1-11. [CrossRef] [PubMed]

85. Kato, A.; Kajiwara, K.; Honda, Y.; Watanabe, M.; Enoki, T.; Yamaguchi, Y.; Kobayashi, T. Efficient field data collection of tropical forest using terrestrial laser scanner. In Proceedings of the 2014 IEEE Geoscience and Remote Sensing Symposium, Quebec City, QC, Canada, 13-18 July 2014; pp. 816-819.

86. Prasada, O.P.; Hussin, Y.A.; Weir, M.J.C.; Karna, Y.K. Derivation of forest inventory parameters for carbon estimation using terrestrial LiDAR. Int. Arch. Photogramm. Remote Sens. Spat. Inf. Sci. ISPRS Arch. 2016, 41, 677-684. [CrossRef]

87. Kankare, V.; Holopainen, M.; Vastaranta, M.; Puttonen, E.; Yu, X.; Hyyppä, J.; Vaaja, M.; Hyyppä, H.; Alho, P. Individual tree biomass estimation using terrestrial laser scanning. ISPRS J. Photogramm. Remote Sens. 2013, 75, 64-75. [CrossRef]

88. Olofsson, K.; Holmgren, J.; Olsson, H. Tree stem and height measurements using terrestrial laser scanning and the RANSAC algorithm. Remote Sens. 2014, 6, 4323-4344. [CrossRef]

89. Liu, J.; Liang, X.; Hyyppä, J.; Yu, X.; Lehtomäki, M.; Pyörälä, J.; Zhu, L.; Wang, Y.; Chen, R. Automated matching of multiple terrestrial laser scans for stem mapping without the use of artificial references. Int. J. Appl. Earth Obs. Geoinf. 2017, 56, 13-23. [CrossRef]

90. Asner, G.P.; Powell, G.V.N.; Mascaro, J.; Knapp, D.E.; Clark, J.K.; Jacobson, J.; Kennedy-Bowdoin, T.; Balaji, A.; Paez-Acosta, G.; Victoria, E.; et al. High-resolution forest carbon stocks and emissions in the Amazon. Proc. Natl. Acad. Sci. USA 2010, 107, 16738-16742. [CrossRef] [PubMed]

91. Asner, G.P.; Mascaro, J. Mapping tropical forest carbon: Calibrating plot estimates to a simple LiDAR metric. Remote Sens. Environ. 2014, 140, 614-624. [CrossRef]

92. Sibona, E.; Vitali, A.; Meloni, F.; Caffo, L.; Dotta, A.; Lingua, E.; Motta, R.; Garbarino, M. Direct Measurement of Tree Height Provides Different Results on the Assessment of LiDAR Accuracy. Forests 2017, 8, 7. [CrossRef]

93. Hancock, S.; Anderson, K.; Disney, M.; Gaston, K.J. Measurement of fine-spatial-resolution 3D vegetation structure with airborne waveform lidar: Calibration and validation with voxelised terrestrial lidar. Remote Sens. Environ. 2017, 188, 37-50. [CrossRef]

94. Odipo, V.; Nickless, A.; Berger, C.; Baade, J.; Urbazaev, M.; Walther, C.; Schmullius, C. Assessment of Aboveground Woody Biomass Dynamics Using Terrestrial Laser Scanner and L-Band ALOS PALSAR Data in South African Savanna. Forests 2016, 7, 294. [CrossRef]

95. Simard, M.; Pinto, N.; Fisher, J.B.; Baccini, A. Mapping forest canopy height globally with spaceborne lidar. J. Geophys. Res. Biogeosci. 2011, 116, 1-12. [CrossRef]

96. Su, Y.; Guo, Q.; Xue, B.; Hu, T.; Alvarez, O.; Tao, S.; Fang, J. Spatial distribution of forest aboveground biomass in China: Estimation through combination of spaceborne lidar, optical imagery, and forest inventory data. Remote Sens. Environ. 2016, 173, 187-199. [CrossRef]

97. Disney, M.I.; Boni Vicari, M.; Calders, K.; Burt, A.; Lewis, S.L.; Raumonen, P.; Wilkes, P. Weighing trees with lasers: Advances, challenges and opportunities. R. Soc. Interface 2018. [CrossRef] [PubMed]

98. Malhi, Y.; Jackson, T.; Patrick Bentley, L.; Lau, A.; Shenkin, A.; Herold, M.; Calders, K.; Bartholomeus, H.; Disney, M.I. New perspectives on the ecology of tree structure and tree communities through terrestrial laser scanning. Interface Focus 2018, 8, 20170052. [CrossRef] [PubMed]

99. Blakey, R.V.; Law, B.S.; Kingsford, R.T.; Stoklosa, J. Remote Sensing of Environment Terrestrial laser scanning reveals below-canopy bat trait relationships with forest structure. Remote Sens. Environ. 2017, 198, 40-51. [CrossRef]

100. Ledo, A.; Cornulier, T.; Illian, J.B.; Iida, Y.; Kassim, A.R.; Burslem, D.F.R.P. Re-evaluation of individual diameter: Height allometric models to improve biomass estimation of tropical trees. Ecol. Appl. 2016, 26, 2376-2382. [CrossRef] [PubMed]

101. Nogueira, E.M.; Nelson, B.W.; Fearnside, P.M.; França, M.B.; de Oliveira, Á.C.A. Tree height in Brazil's 'arc of deforestation': Shorter trees in south and southwest Amazonia imply lower biomass. For. Ecol. Manag. 2008, 255, 2963-2972. [CrossRef]

102. Nogueira, E.M.; Fearnside, P.M.; Nelson, B.W.; França, M.B. Wood density in forests of Brazil's 'arc of deforestation': Implications for biomass and flux of carbon from land-use change in Amazonia. For. Ecol. Manag. 2007, 248, 119-135. [CrossRef]

103. King, D.A. Allometry and life history of tropical trees. J. Trop. Ecol. 1996, 12, 25-44. [CrossRef] 
104. Clark, D.; Clark, D.A. Landscape-scale variation in forest structure and biomass in a tropical rain forest. For. Ecol. Manag. 2000, 137, 185-198. [CrossRef]

105. Lutz, J.A.; Furniss, T.J.; Johnson, D.J.; Davies, S.J.; Allen, D.; Alonso, A.; Anderson-Teixeira, K.J.; Andrade, A.; Baltzer, J.; Becker, K.M.L.; et al. Global importance of large-diameter trees. Glob. Ecol. Biogeogr. 2018, 27, 849-864. [CrossRef] 